\title{
Optimal Degree of Hybridization for Spark-Ignited Engines with Optional Variable Valve Timings
}

\author{
Andyn Omanovic ${ }^{1,2, *}$, Norbert Zsiga ${ }^{1}$, Patrik Soltic ${ }^{1}\left[\right.$ and Christopher Onder ${ }^{2}$ \\ 1 Automotive Powertrain Technologies Laboratory, Empa Swiss Federal Laboratories for Materials Science and \\ Technology, 8600 Dubendorf, Switzerland; norbert.zsiga@protonmail.com (N.Z.); patrik.soltic@empa.ch (P.S.) \\ 2 Institute for Dynamic Systems and Control, ETH Zurich, 8092 Zurich, Switzerland; onder@idsc.mavt.ethz.ch \\ * Correspondence: andyn.omanovic@empa.ch
}

check for

updates

Citation: Omanovic, A.; Zsiga, N.; Soltic, P.; Onder, C. Optimal Degree of Hybridization for Spark-Ignited Engines with Optional Variable Valve Timings. Energies 2021, 14, 8151. https://doi.org/10.3390/en14238151

Academic Editor: Zöldy Máté

Received: 15 November 2021

Accepted: 2 December 2021

Published: 5 December 2021

Publisher's Note: MDPI stays neutral with regard to jurisdictional claims in published maps and institutional affiliations.

Copyright: (c) 2021 by the authors. Licensee MDPI, Basel, Switzerland. This article is an open access article distributed under the terms and conditions of the Creative Commons Attribution (CC BY) license (https:// creativecommons.org/licenses/by/ $4.0 /)$.
Abstract: The electric hybridization of vehicles with an internal combustion engine is an effective measure to reduce $\mathrm{CO}_{2}$ emissions. However, the identification of the dimension and the sufficient complexity of the powertrain parts such as the engine, electric machine, and battery is not trivial. This paper investigates the influence of the technological advancement of an internal combustion engine and the sizing of all propulsion components on the optimal degree of hybridization and the corresponding fuel consumption reduction. Thus, a turbocharged and a naturally aspirated engine are both modeled with the additional option of either a fixed camshaft or a fully variable valve train. All models are based on data obtained from measurements on engine test benches. We apply dynamic programming to find the globally optimal operating strategy for the driving cycle chosen. Depending on the engine type, a reduction in fuel consumption by up to $32 \%$ is achieved with a degree of hybridization of $45 \%$. Depending on the degree of hybridization, a fully variable valve train reduces the fuel consumption additionally by up to $9 \%$ and advances the optimal degree of hybridization to $50 \%$. Furthermore, a sufficiently high degree of hybridization renders the gearbox obsolete, which permits simpler vehicle concepts to be derived. A degree of hybridization of $65 \%$ is found to be fuel optimal for a vehicle with a fixed transmission ratio. Its fuel economy diverges less than $4 \%$ from the optimal fuel economy of a hybrid electric vehicle equipped with a gearbox.

Keywords: hybridization; powertrain modeling; fully variable valve train; engine test bench data; dynamic programming; WLTC

\section{Introduction}

\subsection{Background}

In 2020, the European parliament set the $\mathrm{CO}_{2}$ emission limit for new passenger cars to $95 \mathrm{~g} \mathrm{CO}_{2} / \mathrm{km}$. This corresponds to a gasoline consumption of $4.06 \mathrm{~L} / 100 \mathrm{~km} \mathrm{[1]}$. However, a modern passenger vehicle with a conventional internal combustion engine drive train (ICEV) is not capable of achieving such a low fuel consumption [2]. To avoid penalties for exceeding this limit, car manufacturers are extending the variety of their propulsion technologies. The mobility concepts with a high potential to effectively decrease greenhouse gas (GHG) emissions are plug-in hybrid electric vehicles (PHEV), battery EVs (BEVs), and fuel cell EVs (FCVs) [3]. Currently, the electric energy used to charge EVs is accounted for with zero GHG emissions, independently of its production origin [4-6]. Hence, from a political point of view, purely electric drive trains are the most effective solution to reduce GHG emissions. However, the number of registrations of new BEVs has not yet reached the level of new registrations of ICEVs. This fact is due mainly to the high initial cost for BEVs, which is mostly determined by the capacity of the battery installed $[7,8]$. Furthermore, the, up to this time, insufficient range, the lack of charging stations, and the unknown deterioration of the battery slow the growth of the market share of BEVs $[9,10]$. 


\subsection{Challenges with Regard to the Design and the Operation of Hybrid Electric Vehicles}

A conventional hybrid electric vehicle (HEV) can only be operated in a chargesustaining mode, while a PHEV is capable of driving also in a charge-depleting mode. The charge-sustaining mode is active when the battery is either fully depleted or the manufacturer does not allow the state of charge (SOC) of the battery to diverge significantly from its current state [11-13]. The charge-depleting mode is only enabled if the battery of the vehicle is sufficiently charged, which then allows the vehicle to operate mainly electrically. However, if the charge-depleting mode is not active as often as intended, the actual fuel consumption diverges significantly from the values specified by the legislation [14-17]. Thus, the focus of this paper lies on the sizing and the complexity of the powertrain parts of an HEV such that in the charge-sustaining mode an optimal fuel economy is achieved.

An HEV can be categorized as a P0, P1, P2, P3, or P4 architecture variant, depending on the arrangement of the ICE, the electric machine (EM), and the gearbox. In the architecture variants $\mathrm{P} 0$ and $\mathrm{P} 1$, the EM is attached to the ICE and serves mainly the start/stop operation. The remaining architecture variants allow the EM to be disengaged from the ICE, which enables pure electric operation and efficient recuperation of braking energy [18-22]. Besides the choice of the HEV architecture, the sizing of the EM, the ICE, and the battery is of significant importance concerning fuel economy. If the EM is too small, it cannot recuperate all the braking energy available. In contrast, oversizing the components leads to an excess of vehicle mass, poor efficiency in part-load operation, and an increase in cost [23]. Plenty of research has been invested in the optimization of the powertrain architecture as described in [24-29].

Besides an optimal sizing of the components, an energy management is required such that, compared to an ICEV, with an HEV a lower fuel consumption can be achieved [30-32]. The electric hybridization does not only allow the recuperation of braking energy, but also enables the ICE to run at an efficient operating point [33,34]. The operating points with low power demand, where the ICE exhibits poor efficiency, are driven with the EM in pure electric mode $[35,36]$. In contrast, the ICE is used in operating points with medium to high power demand. If necessary, the load on the ICE can be further increased to simultaneously propel the vehicle and to charge the battery [37]. By increasing the load, this operating point shift (OPS) strategy significantly increases the efficiency of the ICE. The optimal operating strategy can be found with noncausal methods as described in [38-41]. However, due to the high range of feasible input variables, it is difficult to implement a causal operating strategy in an on-road application $[42,43]$, which performs closely to the optimal strategy found by noncausal methods.

\subsection{Our Contribution}

In this paper, we analyze the influence of naturally aspirated and turbocharged sparkignited (SI) engine concepts on the optimal ratio of the maximal power output between the EM and the ICE, which is defined as the degree of hybridization (DOH). The main focus lies in the potential advantage for HEVs when the ICE is equipped with a fully variable valve train (FVVT). An FVVT has been developed internally and tested on a spark-ignited engine. By applying Miller valve timings to achieve the desired engine load instead of adjusting the conventional throttle, the efficiency of the part-load operation is improved [44]. Furthermore, with a cylinder-deactivation mode and the implementation of an x-stroke operation, where the usual four strokes of the engine are extended up to ' $x$ ' strokes, the efficiency of very low engine loads is increased significantly [45]. To solve the optimization task, we apply dynamic programming (DP), which leads to a noncausal but globally optimal operating strategy [46]. Thus, the results presented are treated as a benchmark for the implementation of causal optimization strategies on the test bench in further investigations. To the best of our knowledge, there has been no research conducted yet, which investigates the influence of an FVVT on part-load efficiency of naturally aspirated and turbocharged ICEs in the application of HEVs. 
In ICEVs a gearbox is required to transform low torque values of the engine to high torque values at the wheels, for instance, to accelerate a vehicle from a standstill. If an EM of an HEV exceeds a certain maximal power output, i.e., if a certain DOH is exceeded, the lower gears of the gearbox become redundant since the ICE is not required for the initial acceleration of the vehicle. Thus, we introduce and investigate a vehicle concept where the gearbox is replaced by a fixed transmission drive. This measure reduces the mass of the vehicle and the complexity of the optimization task. Furthermore, in such a setup the EM is well suited for urban usage, while the ICE plays out its advantages on extra-urban routes.

This paper comprises the following points:

- The derivation of the optimal DOH while the 0 to $100 \mathrm{~km} / \mathrm{h}$ acceleration performance of the vehicle for each $\mathrm{DOH}$ is kept constant.

- The analysis of the influence of significant part-load efficiency improvements of the ICE due to the implementation of an FVVT.

- $\quad$ The introduction of a simplified HEV concept without a gearbox.

\section{Simulation Environment and Models}

This section provides an overview of the models implemented. All investigations presented in this paper are conducted with Matlab simulations. The models for the ICEs are based on data obtained from engine test benches, while the model for the EMs is based on results acquired from the finite elements method (FEM) simulations conducted in MotorCAD by AnSys.

\subsection{Parallel Hybrid Electric Vehicle Configuration}

A parallel HEV configuration is chosen such that the ICE is coupled mechanically to the wheels. Hence, if required, any torque from the ICE is transmitted directly to the wheels without any conversion losses over the EM [47-49]. Figure 1 shows the schematics of the vehicle concepts investigated. The schematic in (a) shows an ICEV, i.e., a vehicle where no electric propulsion is available. The ICE is mechanically connected via a clutch, a gearbox, and final drive to the wheels. This concept serves as a reference point regarding fuel consumption. The schematic in (b) shows a parallel HEV concept with a P2 architecture. The vehicle is propelled either by the ICE or the EM, or both simultaneously. The battery of the vehicle is not shown; its capacity depends on the DOH. The schematic in (c) shows a parallel HEV concept with a fixed transmission. Since the torque output of the ICE cannot be sufficiently amplified without high gear ratios, the EM must be strong enough to cover any dynamic torque demands such as, for instance, accelerating the vehicle from a standstill. Thus, this concept is only feasible with a relatively high DOH. As a result, the vehicle is driven purely electric at low velocities such as those typically occurring during urban trips. In contrast, the ICE is used for extra-urban trips, at higher but rather constant velocities. Due to the smaller ICE and the omission of the gearbox, the weight of the vehicle decreases. Furthermore, the reduction of the transmission complexity increases the efficiency of the propulsion path. Since a purely electric operation is foreseen with this concept, an external charging possibility, i.e., a PHEV concept, is recommended. However, since the optimal DOH is evaluated in the charge-sustaining mode, it is irrelevant whether the concept is realized as an HEV or a PHEV.

For our investigations, a mid-class vehicle is chosen with the individual parameters stated in Table 1 . The vehicle base mass $m_{\text {base }}$ accounts only for the chassis of the vehicle but not for the powertrain. The total vehicle mass $m_{v e h}$ is defined as

$$
\mathrm{m}_{\mathrm{veh}}=\mathrm{m}_{\text {base }}+\mathrm{m}_{\mathrm{GB} / \mathrm{FT}}+\mathrm{m}_{\mathrm{ICE}}+\mathrm{m}_{\mathrm{EM}}+\mathrm{m}_{\mathrm{bat}} .
$$

Depending on the HEV concept selected, either the mass of a gearbox $\mathrm{m}_{\mathrm{GB}}$ or the mass of a fixed transmission $\mathrm{m}_{\mathrm{FT}}$ is included. The masses of the ICE $\mathrm{m}_{\mathrm{ICE}}$, the EM $\mathrm{m}_{\mathrm{EM}}$, and the battery $\mathrm{m}_{\text {bat }}$ depend on the $\mathrm{DOH}$, i.e., the power required of each component. Once the power requirements are known, the mass is computed with the specific power-to-mass 
ratios. The gear ratios are taken from an existing seven-speed gearbox of a mid-class vehicle. The axle ratio is chosen such that in the highest gear and at an engine speed of $2000 \mathrm{rpm}$ a vehicle speed of $100 \mathrm{~km} / \mathrm{h}$ is achieved.

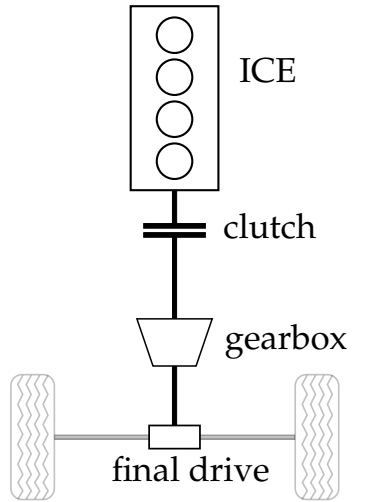

(a) ICEV

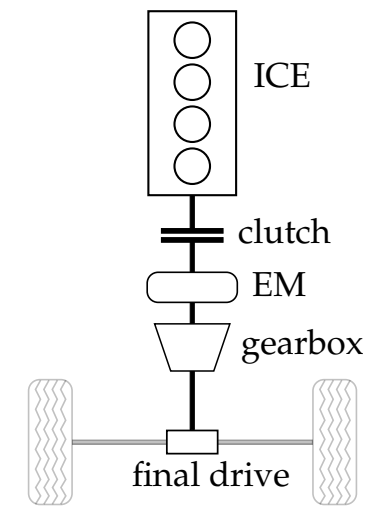

(b) HEV

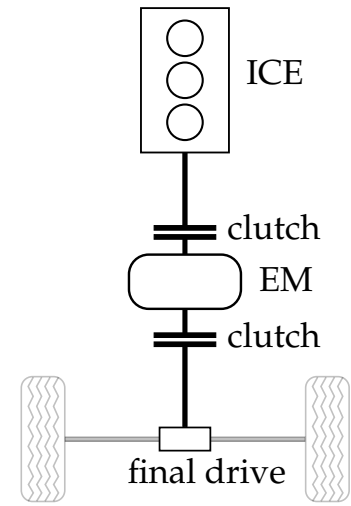

(c) FTHEV

Figure 1. Schematic representation of the parallel hybrid vehicle designs investigated, where (a) is an ICEV and serves as a reference design with regard to the fuel consumption, (b) is an HEV (also possible as PHEV) realized with a P2 architecture, and (c) is an HEV concept with a high DOH (thus rather but not necessarily a PHEV) without a gearbox but with a fixed transmission ratio.

Table 1. Mid-class vehicle parameters.

\begin{tabular}{lccc}
\hline Parameter & Symbol & Value & Unit \\
\hline Aerodynamic drag coefficient & $\mathrm{c}_{d}$ & 0.3 & - \\
Frontal area & $\mathrm{A}_{f}$ & 2.2 & $\mathrm{~m}^{2}$ \\
Rolling resistance coefficient & $\mu_{r}$ & 0.01 & - \\
Wheel radius & $\mathrm{w}_{r}$ & 0.3 & $\mathrm{~m}$ \\
Vehicle base mass & $\mathrm{m}_{\mathrm{base}}$ & 1350 & $\mathrm{~kg}$ \\
Gearbox mass & $\mathrm{m}_{\mathrm{GB}}$ & 75 & $\mathrm{~kg}$ \\
Fixed transmission mass & $\mathrm{m}_{\mathrm{FT}}$ & 10 & $\mathrm{~kg}$ \\
Gearbox efficiency & $\eta_{\mathrm{GB}}$ & 0.95 & - \\
Fixed transmission efficiency & $\eta_{\mathrm{FT}}$ & 0.975 & - \\
Specific power ICE & $\mathrm{p}_{\mathrm{ICE}}$ & 800 & $\mathrm{~W} / \mathrm{kg}$ \\
Specific power EM & $\mathrm{p}_{\mathrm{EM}}$ & 3000 & $\mathrm{~W} / \mathrm{kg}$ \\
Specific capacity battery & $\mathrm{p}_{\mathrm{bat}}$ & 180 & $\mathrm{Wh} / \mathrm{kg}$ \\
C-rate battery & $\mathrm{C}_{\mathrm{bat}}$ & 5 & - \\
Gear ratios & $\mathrm{r}_{\mathrm{gear}}$ & {$[3.19,2.19,1.52,1.06,0.74,0.56,0.43]$} & - \\
Axle ratio & $\mathrm{r}_{\mathrm{ax}}$ & 5.26 & - \\
ICE speed range & - & $1000-6000$ & $\mathrm{rpm}$ \\
\hline
\end{tabular}

\subsection{Dynamic Programming and Driving Cycle}

The simulation uses a quasistatic approach in which all state variables, such as the torque required at the wheel, remain constant for the duration of the time step. The driving cycle implemented is the worldwide harmonized light vehicle test cycle (WLTC) of Class 3 with a step resolution of $1 \mathrm{~s}$, as shown in Figure 2.

An HEV in such a setup has two degrees of freedom, namely

- the power split factor between the EM and the ICE,

- $\quad$ and the choice of the gear.

Thus, the optimization variables $u_{1}$ for the power split factor and $u_{2}$ for the gear are defined in Table 2. 


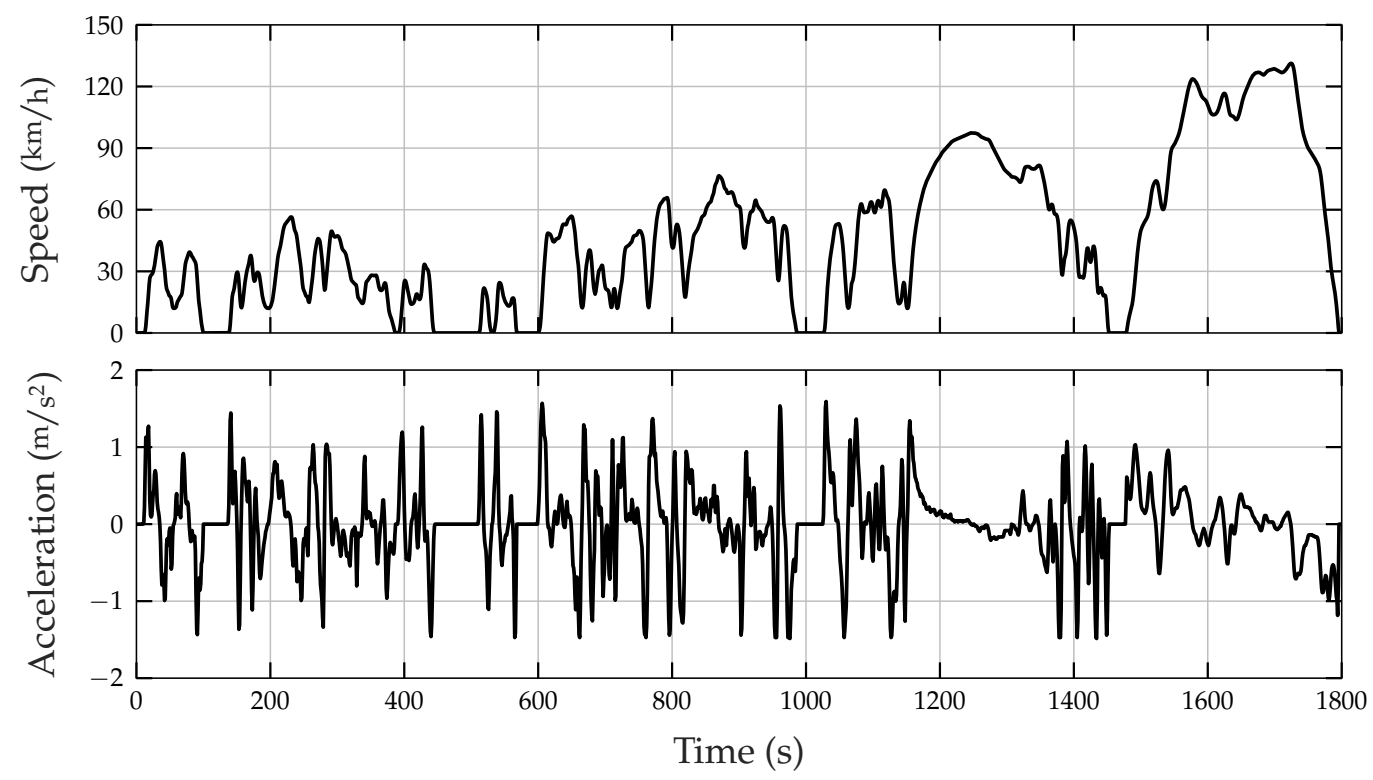

Figure 2. Speed and acceleration data of the worldwide harmonized light vehicle test cycle (WLTC) of Class 3.

Table 2. Optimization variables.

\begin{tabular}{ccr}
\hline Variable & Range & Description \\
\hline Power split $u_{1}$ & -1 & ICE used for maximal recharging \\
Power split $u_{1}$ & $-1-0$ & ICE used for recharging and propulsion \\
Power split $u_{1}$ & 0 & Only ICE used for propulsion \\
Power split $u_{1}$ & $0-1$ & ICE and EM used for propulsion \\
Power split $u_{1}$ & 1 & Only EM used for propulsion \\
Gear $u_{2}$ & $1-7$ & Choice of gear \\
\hline
\end{tabular}

We apply dynamic programming to find the fuel-minimizing set of $u_{1}$ and $u_{2}$ that guarantees charge-sustaining operation, i.e., that the SOC of the battery at the end of the cycle reaches the value given initially. In [50], a DP script is provided for use within Matlab. DP creates a grid for each time step and each state that is reachable by the optimization variables. Subsequently, beginning from the final state, a backward calculation is performed where for each grid point the torque delivered by the EM and the ICE, the power from or to the battery resulting in a new SOC, and the instantaneous fuel consumption are evaluated. For each time step, the set of $u_{1}$ and $u_{2}$ is determined that is feasible and minimizes the cost criteria, in this case, the fuel consumption of the ICE. As the algorithm propagates backward, each new set of $u_{1}$ and $u_{2}$ is added to the optimal control input vector. The calculation terminates after reaching the initial time step. Due to the principle of optimality, the solution found by DP through backward calculation is guaranteed to be globally optimal [46,51-53].

\subsection{Internal Combustion Engine Model}

In this paper, a naturally aspirated (NA) and a turbocharged (TC) SI engine are analyzed. The choice of a valve train system, i.e., either a fixed camshaft or a fully variable valve train and its influence on the fuel consumption are investigated for both engine types. The model for the naturally aspirated engine is based on data obtained from measurements on a 20182.5 L Atkinson cycle engine with cooled exhaust gas recirculation [54]. The turbocharged engine is modeled with own data obtained from measurements on an engine test bench equipped with a $3.0 \mathrm{~L}$ direct-injected SI engine. The increase of the indicated efficiency in part-load operation due to an FVVT is additionally quantified on an engine test bench with a four-cylinder 1.4 L SI engine equipped with an internally developed 
FVVT [45]. All results are expressed in units that allow a comparison of engines with different displacement volumes [55]. As described in [56], the fuel flow is expressed as the mean fuel pressure $p_{\mathrm{m} \varphi}$ and is computed as

$$
p_{\mathrm{m} \varphi}=\frac{H_{l} \cdot m_{\varphi, \mathrm{cyc}}}{V_{d}}
$$

where $H_{l}$ is the lower heating value of the fuel in $\mathrm{J} / \mathrm{kg}, m_{\varphi, \text { cyc }}$ is the fuel mass injected during one engine cycle in $\mathrm{kg}$, and $V_{d}$ is the displacement volume in $\mathrm{m}^{3}$. The mean indicated pressure $p_{\mathrm{mi}}$, i.e., the integral of the pressure over the volume for one engine cycle, divided by $p_{\operatorname{m} \varphi}$ yields the indicated efficiency $\eta_{\text {ind }}$, i.e.,

$$
\eta_{\text {ind }}=\frac{p_{\mathrm{mi}}}{p_{\mathrm{m} \varphi}} .
$$

Figure 3 shows the models of the indicated efficiency of four different engines at an engine speed of $2500 \mathrm{rpm}$. The solid lines represent the indicated efficiency of the engines with a camshaft and are fitted to data obtained from measurements on the test benches. The dashed lines show the potential gain in efficiency if the engines are equipped with an FVVT. The first observation is that the FVVT allows the pumping losses to be reduced from approximately 0.4 bar to 0.2 bar for an operating point with $p_{\mathrm{mi}}=2$ bar. For the engine with the camshaft as well as for the engine with the FVVT, the pumping losses decrease linearly to a minimum of approximately 0.05 bar as the load increases. Second, an FVVT enables the engine to run part-load operating points in an x-stroke operation or with deactivated cylinders, which significantly increases the indicated efficiency as shown in [45]. The lines colored represent NA engines with a maximal value of $p_{\mathrm{mi}}$ of approximately 12.5 bar while the black lines represent TC engines with a maximal $p_{\mathrm{mi}}$ of approximately 22 bar. The studies with the FVVT conducted thus far were focused on the efficiency improvement in part-load operating points. Thus, an improvement in indicated efficiency is only achieved for operating points with a $p_{\mathrm{mi}}$ value of $<11$ bar.

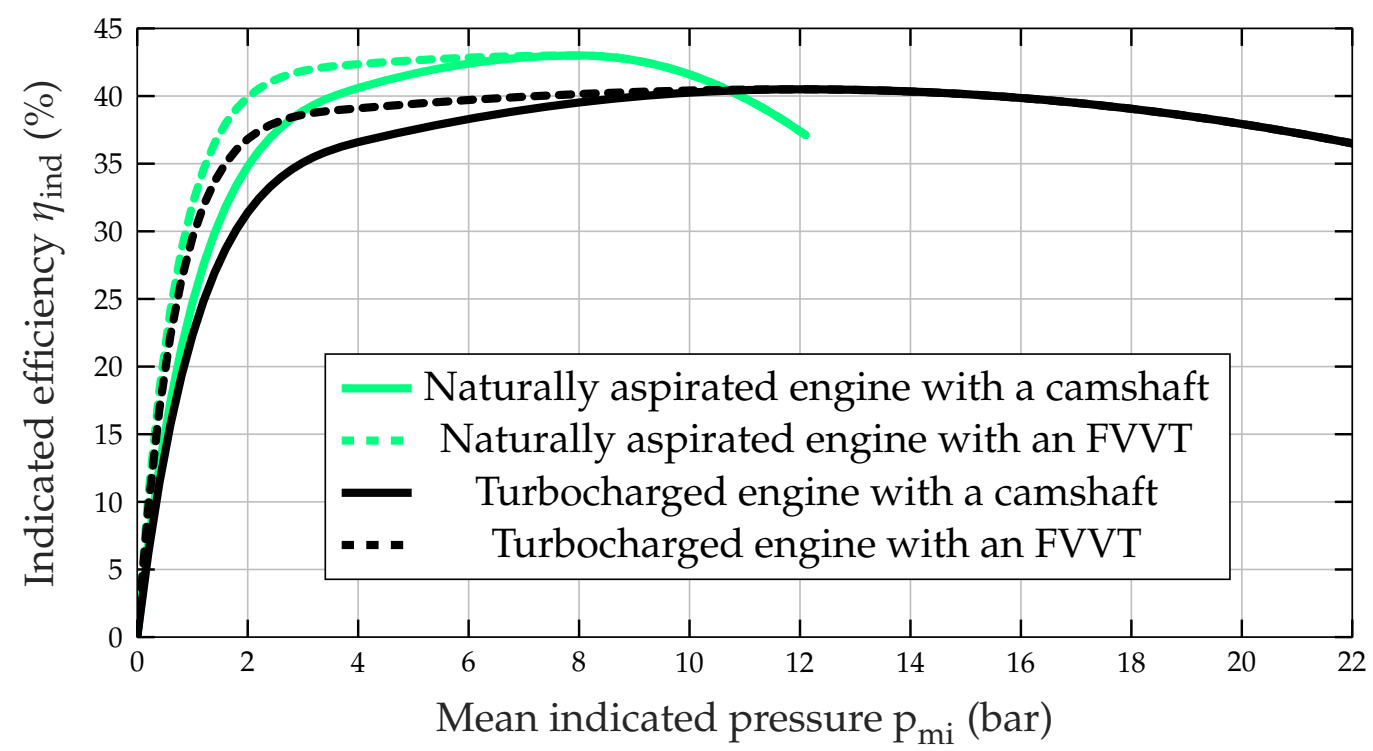

Figure 3. Plot allowing a comparison of the indicated efficiency of four different engine concepts. The lines colored show the indicated efficiency for a naturally aspirated engine, while the black lines show the indicated efficiency for a turbocharged engine. In the case of the solid lines, the engines are equipped with a camshaft, while in the case of the dashed lines, an FVVT is implemented instead. 
The mean effective pressure $p_{\mathrm{me}}$ is a sum of the mean indicated pressure $p_{\mathrm{mi}}$ and the mean friction pressure $p_{\mathrm{mf}}$. As described in [56], for a four-stroke operated engine it is computed as

$$
p_{\mathrm{me}}=p_{\mathrm{mi}}-p_{\mathrm{mf}}=4 \cdot \pi \cdot \frac{T_{\mathrm{e}}}{V_{d}} .
$$

Here, $T_{\mathrm{e}}$ is the effective engine torque measured at the dynamometer in $\mathrm{Nm}$. With Equations (2) and (4) the engine brake efficiency $\eta_{\text {brake }}$ is computed as

$$
\eta_{\text {brake }}=\frac{p_{\mathrm{me}}}{p_{\mathrm{m} \varphi}} .
$$

Resulting from Equation (5), Figure 4 shows the brake efficiency models on the lefthand side for a TC engine and on the right-hand side for an NA engine. The $\mathrm{x}$ axis shows the engine speed range in rpm while the y axis shows the mean effective pressure $p_{\text {me }}$ in bar. In the upper two plots the iso-efficiency lines show the brake efficiency in $\%$, while in the lower two plots, the results show the brake efficiency improvement in $\%$ that is due to an FVVT.

At the minimal speed of $1000 \mathrm{rpm}$, the maximal engine output of the NA engine equals to a $p_{\text {me }}$ value of 8 bar. From $1000 \mathrm{rpm}$ to $2000 \mathrm{rpm}$ the maximal engine output increases linearly up to a $p_{\mathrm{me}}$ value of $11 \mathrm{bar}$ where it remains constant up to $6000 \mathrm{rpm}$. Equipped with a camshaft, the engine achieves a maximal brake efficiency of $39 \%$. The plot in the lower right corner shows the improvement in efficiency due to an FVVT installed on the NA engine. For very low loads, i.e., $p_{\mathrm{me}} \approx 0.5 \mathrm{bar}$, the FVVT improves the brake efficiency depending on the engine speed by approximately $40 \%$ to $30 \%$. As the load increases, this advantage decreases to around $0 \%$ for $p_{\text {me }} \approx 10$ bar.

At the minimal speed of $1000 \mathrm{rpm}$, the maximal engine output of the TC engine equals to a $p_{\text {me }}$ value of 13 bar. From $1000 \mathrm{rpm}$ to $2000 \mathrm{rpm}$ the maximal engine output increases linearly up to a $p_{\text {me }}$ value of 20 bar where it remains constant up to $5000 \mathrm{rpm}$. From $5000 \mathrm{rpm}$ up to $6000 \mathrm{rpm}$ the power output of the engine remains approximately constant, causing the mean effective pressure to decrease accordingly to 18 bar. Equipped with a camshaft, the engine achieves a maximal brake efficiency of 37\%. The plot in the lower left corner shows the improvement in efficiency that is due to an FVVT installed on the TC engine. For very low loads, i.e., $p_{\mathrm{me}} \approx 0.5 \mathrm{bar}$, the FVVT improves the brake efficiency depending on the engine speed by approximately $40 \%$ to $25 \%$. As the load increases, this advantage decreases to around $0 \%$ for $p_{\mathrm{me}} \approx 10$ bar.

An FVVT is especially advantageous for part-load operation. Improvements in efficiency thus occur only below a $p_{\text {me }}$ value of 10 bar for TC engines as well as for NA engines. Thus, for a TC engine, the improvements induced by an FVVT affect approximately half of the operating range. However, in the case of an NA engine, an FVVT improves the efficiency for almost the entire operating range. For driving cycles with a low power demand, such as the New European Driving Cycle (NEDC), operating points between 2 bar and 4 bar $p_{\text {me }}$ occur frequently. At those operating points, an FVVT improves the brake efficiency by $10 \%$ to $20 \%$ for both engine types.

With the operating point defined by the driving cycle, i.e., the required load and the rotational speed, and the brake efficiency map, the fuel flow $\dot{m}_{\varphi}$ is computed in $\mathrm{kg} / \mathrm{s}$ for each time step by reordering and extending Equation (5) to

$$
\dot{m}_{\varphi}=\frac{p_{\mathrm{m} \varphi} \cdot V_{d} \cdot \omega_{e}}{H_{l} \cdot 4 \cdot \pi},
$$

where $\omega_{e}$ describes the rotational engine speed in $\mathrm{rad} / \mathrm{s}$. 


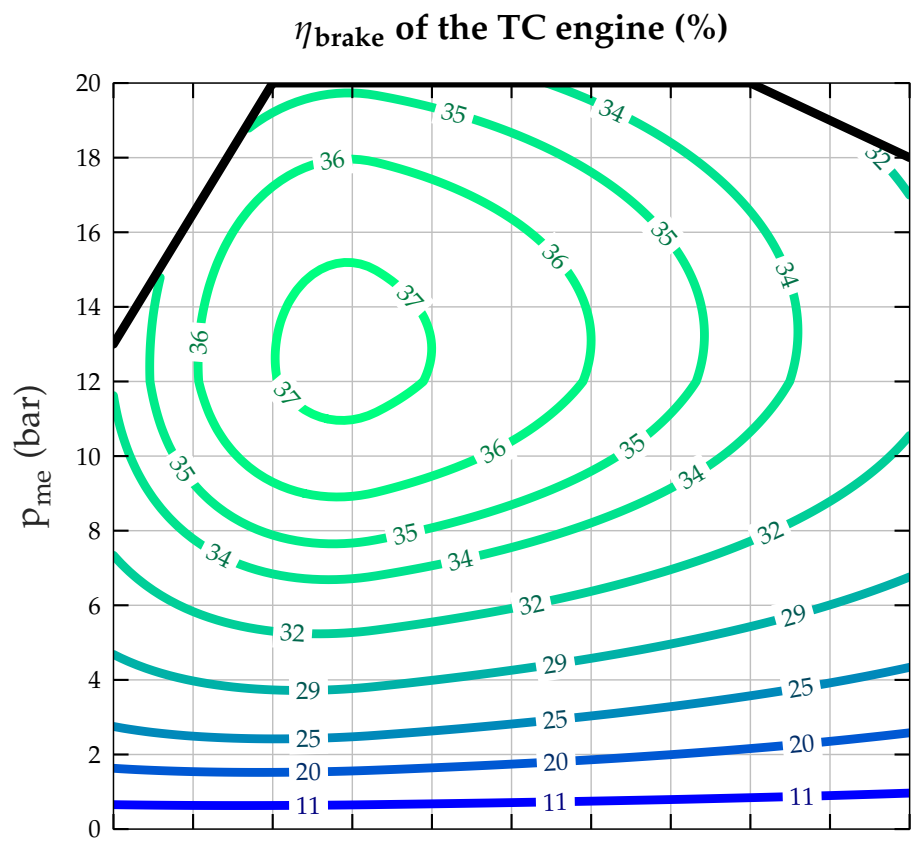

$\eta_{\text {brake improvement due to an FVVT (\%) }}$

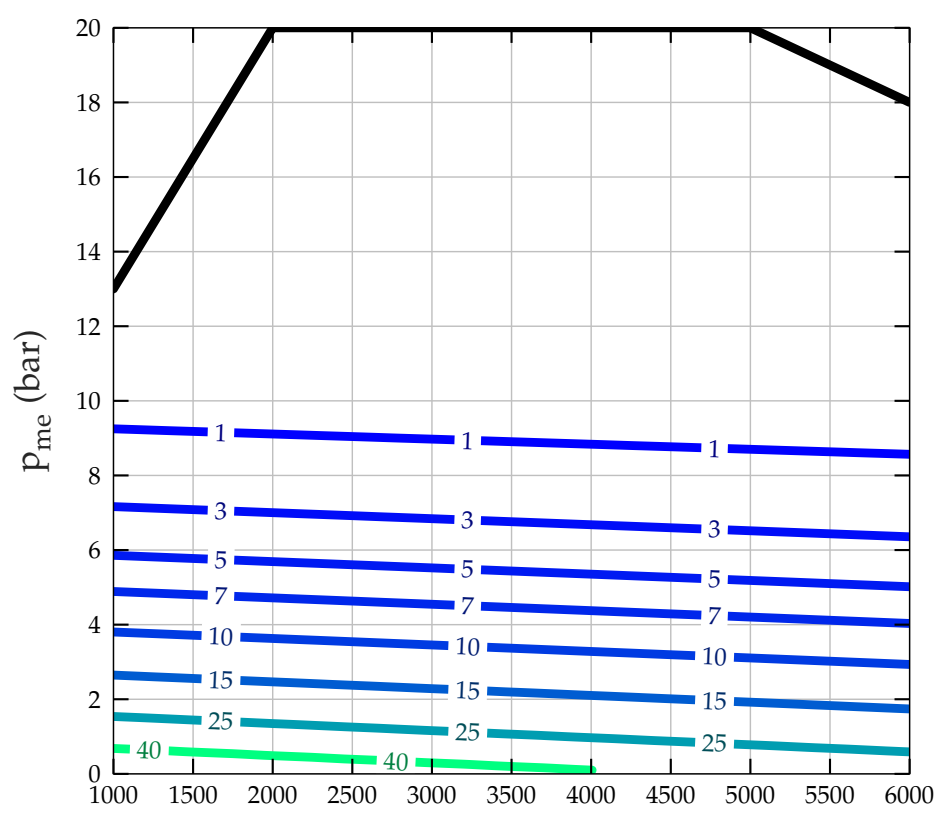

$\eta_{\text {brake }}$ of the NA engine (\%)

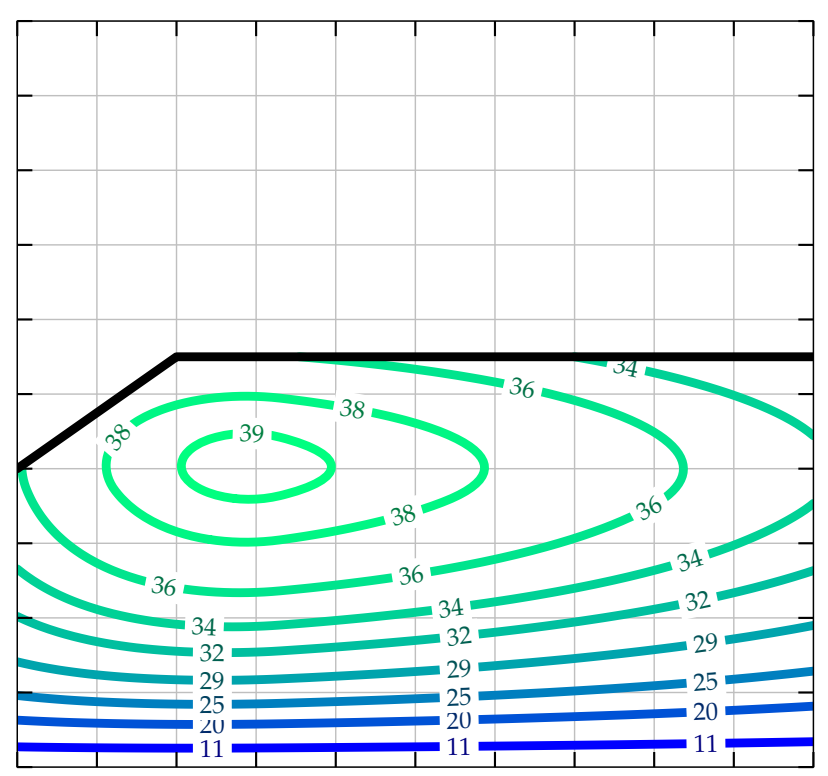

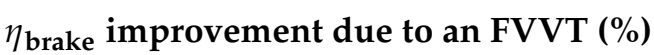

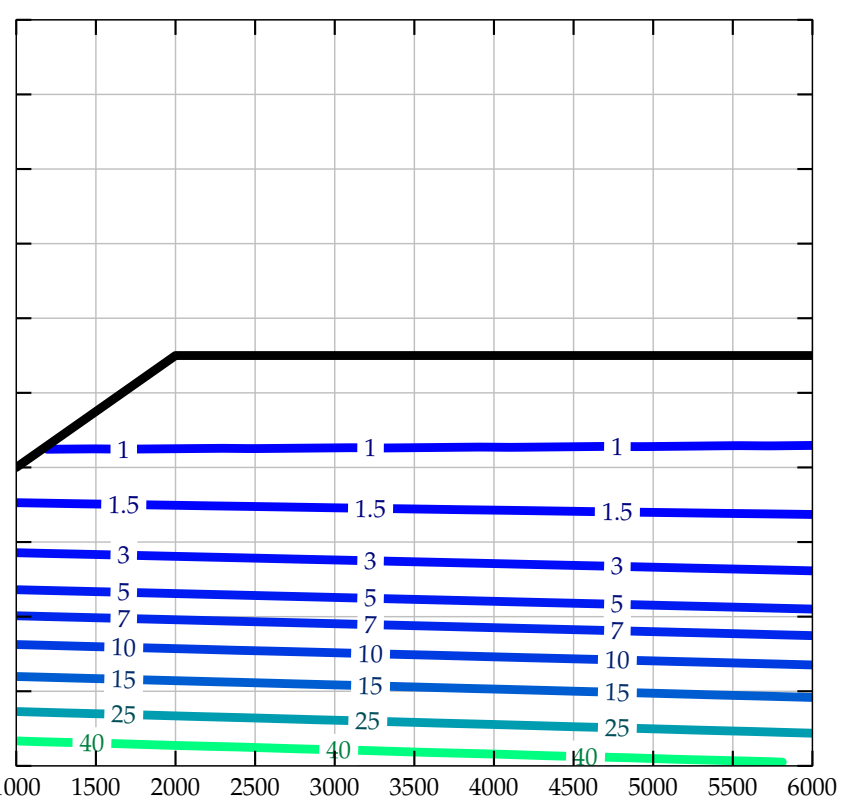

Figure 4. Brake efficiency maps fitted to the data obtained from measurements. The maps on the left-hand side stem from a TC engine while the maps on the right-hand side stem from an NA engine. The upper plots show the brake efficiency of camshaft-driven engines while the lower maps show the improvement in efficiency for the same engines but with an FVVT instead.

\subsection{Electric Machine Model}

The efficiency map for the electric machine, i.e., the motor and the generator, is obtained from FEM simulations in MotorCAD. MotorCAD is a simulation software owned by AnSys which is specifically created to design electric machines. Figure 5 shows the efficiency map for a reference machine with a maximum power output of $150 \mathrm{~kW}$. For the current investigation, the range of the rotational speed of the electric machine matches the possible engine speed. Investigations documented in [57-59] show that the efficiency maps of electric machines of varying power ranges look similar as long as the ratio of the constant torque to constant power region and the type of EM remain constant. Thus, for 
the variation of the $\mathrm{DOH}$, the $\mathrm{y}$ axis, i.e., the torque output, of the reference map in Figure 5 is scaled accordingly.

\section{Electric machine efficiency (\%)}

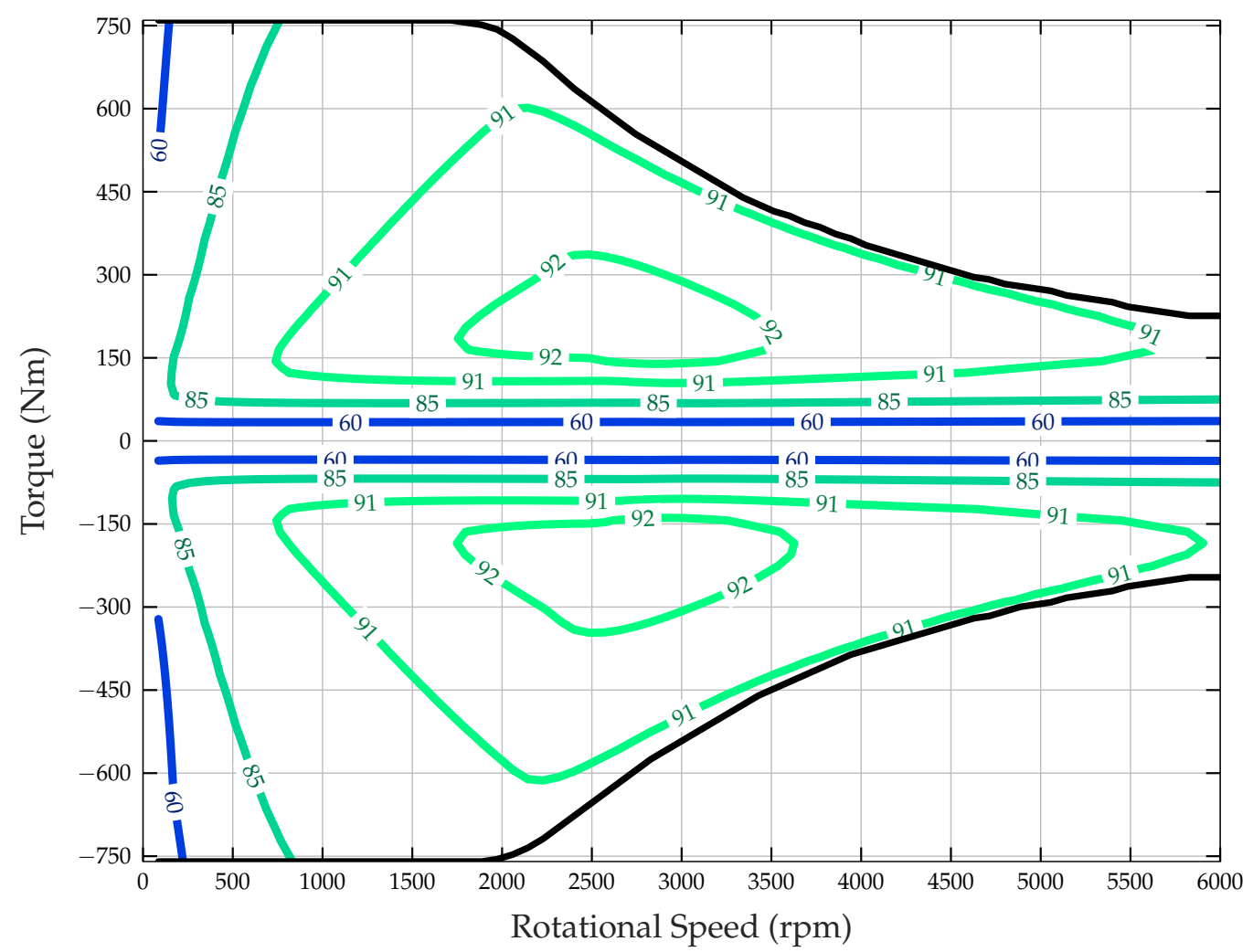

Figure 5. Efficiency map of an electric machine $(150 \mathrm{~kW})$ obtained from FEM simulations in MotorCAD by AnSys.

\subsection{Battery Model}

The battery pack is based on a cell by Panasonic of the type NCR18650B with a nominal cell voltage $U_{\text {nom,cell }}$ of $3.6 \mathrm{~V}$ and a capacity $C_{\text {cell }}$ of $3.2 \mathrm{Ah}$. Figure 6 shows the characteristics of the cell taken from the cell data sheet created by Panasonic [60]. The upper plot shows the open-circuit voltage $U_{\mathrm{oc} \text {,cell }}$ in $\mathrm{V}$ over the state of charge, while the lower plot shows the discharge resistance $R_{\text {dis,cell }}$ as a solid line and the charge resistance $R_{\text {char,cell }}$ as a dashed line, both in $\mathrm{m} \Omega$. Both resistance curves are plotted over the state of charge. The nomenclature used in this paper is as follows: A battery pack consists of multiple battery modules, each of which consists of multiple cells. Those cells are connected in series, while modules are connected in parallel. Hence, the number of cells per module $n_{\text {cell }}$ defines the nominal voltage of the battery pack which here is set to $360 \mathrm{~V}$, i.e., 100 cells per module. Furthermore, the capacity of the battery is made dependent on the DOH, i.e., on the maximal power of the EM, such that the maximal c-rate is always guaranteed. The specific mass assumed of the battery pack including packaging is $180 \mathrm{Wh} / \mathrm{kg}$.

With

$$
\begin{aligned}
& U_{\mathrm{oc}, \bmod }=n_{\text {cell }} \cdot U_{\mathrm{oc}, \mathrm{cell}}, \\
& E_{\text {mod }}=n_{\text {cell }} \cdot C_{\text {cell }} \cdot U_{\text {nom,cell }} \text {, } \\
& R_{\text {dis,mod }}=n_{\text {cell }} \cdot R_{\text {dis,cell }} \text {, } \\
& R_{\text {char,mod }}=n_{\text {cell }} \cdot R_{\text {char,cell, }}
\end{aligned}
$$

the open circuit voltage $U_{\mathrm{oc} \text {,mod }}$ in $\mathrm{V}$, the capacity $E_{\text {mod }}$ in Wh, and the discharge and charge resistances $R_{\text {dis,mod }}$ and $R_{\text {char,mod }}$ in $\Omega$, of the battery modules are calculated [61]. 
The number of required modules $n_{\text {mod }}$ depends of the desired battery pack capacity $E_{\text {pack }}$. Subsequently, the open circuit voltage $U_{\mathrm{oc} \text {,pack }}$ and the discharge and charge resistances $R_{\text {dis,pack }}$ and $R_{\text {char,pack }}$ are modeled as follows:

$$
\begin{array}{r}
n_{\text {mod }}=\frac{E_{\text {pack }}}{E_{\mathrm{mod}}}, \\
U_{\mathrm{oc}, \text { pack }}=U_{\mathrm{oc, \text {mod }}}, \\
R_{\text {dis,pack }}=\frac{R_{\mathrm{dis}, \text { mod }}}{n_{\mathrm{mod}}}, \\
R_{\text {char,pack }}=\frac{R_{\mathrm{char} \text { mod }}}{n_{\mathrm{mod}}} .
\end{array}
$$
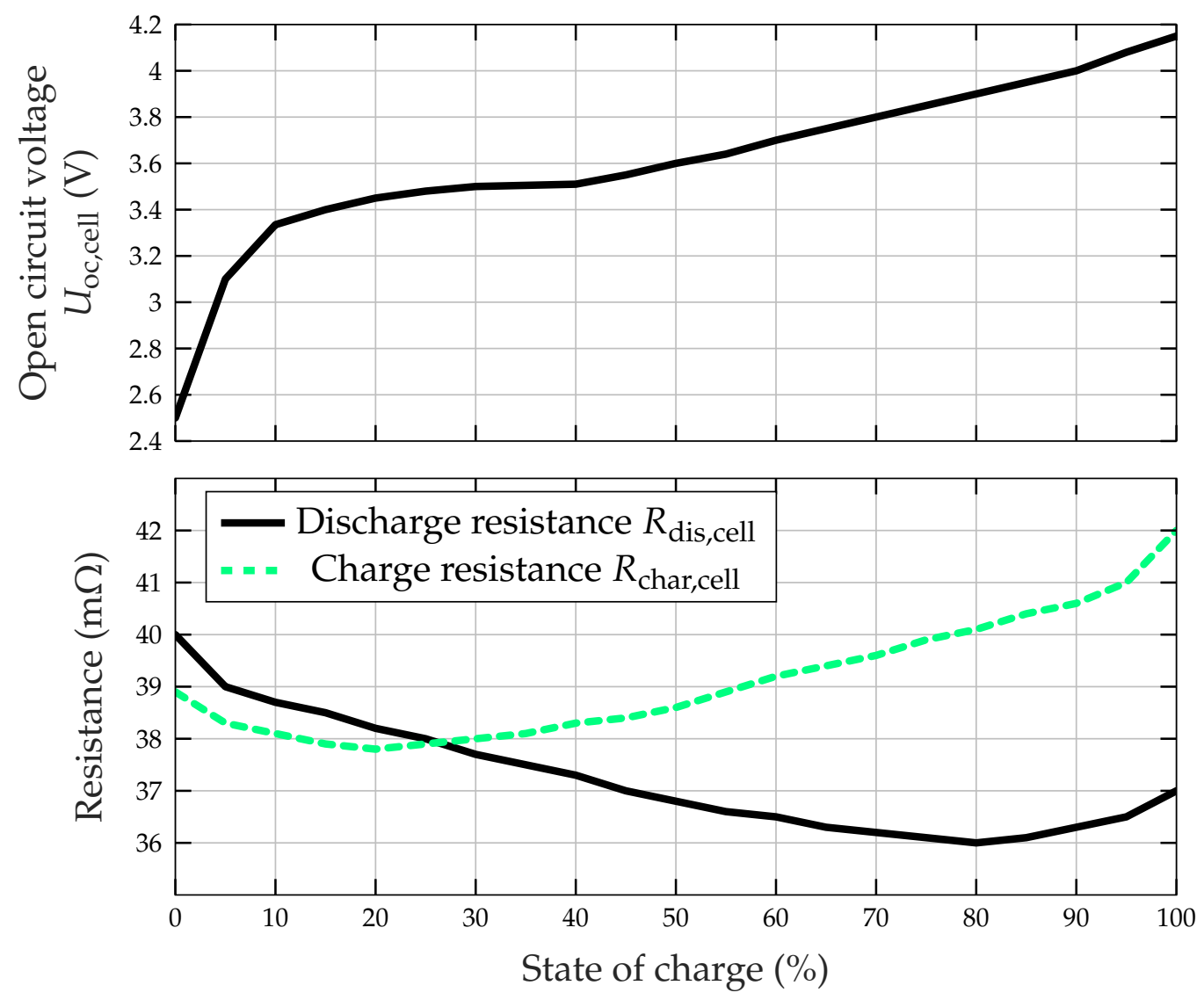

Figure 6. Open-circuit voltage and resistance characteristics of the Panasonic cell of the type NCR18650B.

\subsection{Degree of Hybridization}

The DOH is defined as

$$
\mathrm{DOH}=\frac{P_{\mathrm{EM}, \max }}{P_{\mathrm{EM}, \max }+P_{\mathrm{ICE}, \max }},
$$

where $P_{\mathrm{EM}, \max }$ is the maximal power output of the electric machine and $P_{\mathrm{ICE}, \max }$ is the maximal power output of the internal combustion engine. Thus, a $\mathrm{DOH}$ of $0 \%$ corresponds to a conventional vehicle with an ICE as the only propulsion system. On the other hand, a $\mathrm{DOH}$ of $100 \%$ corresponds to a fully electric vehicle. For each $\mathrm{DOH}$ a unique combination of $P_{\mathrm{EM}, \mathrm{max}}$ and $P_{\mathrm{ICE}, \mathrm{max}}$ exists. Since the power-to-mass ratios of the two propulsion technologies differ, the mass of the vehicle varies in accordance with the DOH. However, the total system power $P_{\text {tot }}$ is not defined by the DOH. To acquire comparable results, $P_{\text {tot }}$ 
is set for each $\mathrm{DOH}$ such that the time to accelerate the vehicle from standstill to $100 \mathrm{~km} / \mathrm{h}$ is constant at $8 \mathrm{~s}$. The acceleration performance $t_{0-100 \mathrm{~km} / \mathrm{h}}$ is a function of $P_{\text {tot }}$ and $m_{\mathrm{veh}}$. However, $m_{\mathrm{veh}}$ itself is a function of $P_{\text {tot }}$. Thus, the equation

$$
t_{0-100 \mathrm{~km} / \mathrm{h}}=f\left(P_{\text {tot }}, m_{\mathrm{veh}}\right)=f\left(P_{\text {tot }}, f\left(P_{\text {tot }}\right)\right)
$$

is solved iteratively.

In Figure 7, the upper plot shows the progression of the maximal propulsion power and of the battery capacity while the lower plots show the progression of the vehicle mass as a function of the DOH. The feasible upper limit of the $\mathrm{DOH}$ is found to be $85 \%$. A $\mathrm{DOH}$ of $90 \%$ results in an ICE with a maximal power output of approximately $10 \mathrm{~kW}$. However, the average power demand of the WLTC for the given vehicle is approximately $11 \mathrm{~kW}$. Thus, a DOH greater than $85 \%$ leads to an under-dimensioned ICE that is not able to drive the WLTC in the charge-sustaining mode, which renders the results unsuitable for comparisons.

Vehicles with TC engines

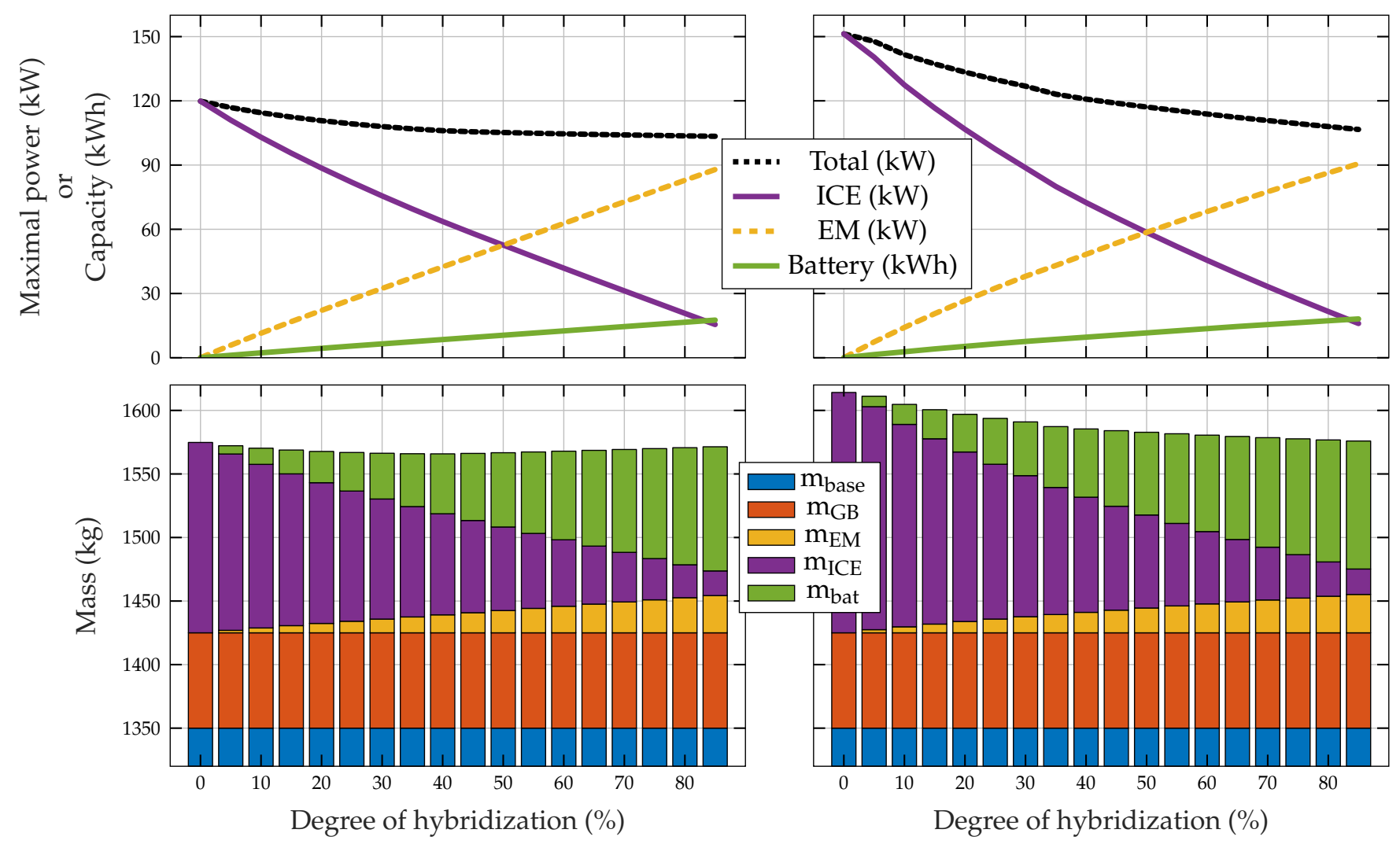

Figure 7. Effects of the degree of hybridization on the maximal power and the mass distribution of the vehicle and its components. The plots on the left-hand side show the results from vehicles equipped with a turbocharged ICE, while the plots on the right-hand side show the results from vehicles with naturally aspirated ICEs.

The plots on the left-hand side show the results of vehicles with a TC engine. In addition, the plots on the right-hand side show the results of vehicles with an NA engine. These results are independent of the valve train system, whether that is a camshaft or an FVVT system. The lower plots show that in both cases the base mass $m_{\text {base }}$ and the gearbox mass $m_{\mathrm{GB}}$ remain constant with values of $1350 \mathrm{~kg}$ and $75 \mathrm{~kg}$, respectively. The mass of a vehicle with a TC engine and a DOH of $0 \%$ is $1575 \mathrm{~kg}$, which decreases as the $\mathrm{DOH}$ increases. At a DOH of $40 \%$, a minimal vehicle mass of $1566 \mathrm{~kg}$ is calculated. An increase of the DOH above $40 \%$ induces an increase in the vehicle mass. The power-to-mass ratio is significantly better for EMs than for ICEs. Thus, electrification of the propulsion 
system leads to a decrease in total mass. However, to maintain a constant c-rate, the battery must be scaled in accordance with the EM. Above a DOH of $40 \%$, the mass of the battery compensates the mass advantages due to the EM and leads to an increase of the total vehicle mass. In contrast, the power-to-mass ratio of an NA engine is lower than that of a TC engine, which leads to an overall higher vehicle mass. An ICEV with an NA engine has a mass of $1614 \mathrm{~kg}$, which is approximately $2 \%$ more than the ICEV with a TC engine. Furthermore, despite a larger battery, the total mass decreases at an increasing $\mathrm{DOH}$ due to the mass savings resulting from a smaller NA engine. Thus, the minimal mass of a vehicle with an NA engine is $1576 \mathrm{~kg}$ which is found at a DOH of $85 \%$, which is the upper limit of these investigations. Without regard to the engine type, the upper plots indicate a monotonic decrease of the maximal vehicle power required for the desired performance from a standstill to $100 \mathrm{~km} / \mathrm{h}$. This is explained by the fact that the acceleration performance is not only dependent on the vehicle mass attained, but also on the torque available. Since an EM allows outputting its maximal torque basically from a standstill, the acceleration performance of the vehicle improves with the increase of the $\mathrm{DOH}$, that is with the increase of the torque available from the EM, despite reduced maximal power.

\section{Influence of the Degree of Hybridization on the Fuel Consumption}

In this section, the $\mathrm{DOH}$ is varied for the HEV concepts introduced in Figure 1. To obtain comparable results of various degrees of hybridization, all vehicles must be operated in the charge-sustaining mode. This means that the SOC of the battery at the end of the test cycle must be identical to the one at the beginning. Thus, it is irrelevant if the concept analyzed is an HEV without external charging possibility or a PHEV with external charging possibility. The operating strategy for each vehicle configuration is obtained with DP and therefore is globally optimal. However, the optimal solution is not necessarily implementable due to, for instance, abrupt changes in the choice of the power split, i.e., the power demand of the ICE and the EM. The development of an operating strategy that is feasible for implementation in the real world is subject to further investigations.

\subsection{HEV with a Gearbox}

This section analyzes the influence of the DOH on the fuel consumption for the HEV concept (b) depicted in Figure 1.

The upper plot in Figure 8 shows the relative fuel consumption over the DOH of all the engine concepts investigated. Here, all results are relative to the fuel consumption value of $100 \%$ of the vehicle with a camshaft-equipped TC engine at a DOH of $0 \%$. Compared to the reference vehicle, the fuel consumption of an $\mathrm{HEV}$ with a $\mathrm{DOH}$ of $10 \%$ and a camshaft-equipped TC engine is reduced by approximately $22 \%$. Most of the fuel-saving potential is exploited at a $\mathrm{DOH}$ of $25 \%$, where a reduction of approximately $28 \%$ is achieved. The fuel-optimal HEV configuration is found at a DOH of $45 \%$ with a fuel consumption reduction of $29.2 \%$. HEVs with an NA engine follow a similar tendency. However, at the same degree of hybridization, the fuel consumption of NA engines, on average, decreases by more than $2 \%$ further than it does for TC engines. A small degree of hybridization allows the operating points to be shifted towards peak efficiency, which for the modeled NA engine is approximately $2 \%$ higher than for the TC engine. Hence, an HEV with a camshaft-equipped NA engine at its fuel-optimal DOH of $45 \%$ reaches a fuel consumption reduction of approximately $31.9 \%$. As stated above, in the case of NA engine-equipped $\mathrm{HEVs}$ the fuel-saving potential is exploited at a DOH of $25 \%$ with an achieved reduction of the fuel consumption of approximately 30\%. Furthermore, for both TC and NA engines, an FVVT reduces the fuel consumption over the complete $\mathrm{DOH}$ range investigated. For greater detail, the lower plot shows the improvement in fuel consumption due to the FVVT over the $\mathrm{DOH}$ in $\%$. These results are relative to their corresponding engine type, TC and NA, respectively. An FVVT reduces the fuel consumption by $4 \%$ to $9 \%$ for the ICEV at a $\mathrm{DOH}$ of $0 \%$, which agrees with the results published in [62]. However, the benefit of an 
FVVT vanishes rapidly as the $\mathrm{DOH}$ increases. At a $\mathrm{DOH}$ of $10 \%$, the reduction of the fuel consumption due to the FVVT reaches $3.6 \%$ at the most. For FVVT-equipped engines, the optimal HEV configuration is slightly shifted to a DOH of $50 \%$ for HEVs with a TC engine as well as for HEVs with an NA engine. At the fuel-optimal DOH, the FVVT improves the fuel consumption for HEVs with NA engines by $1.7 \%$ and for HEVs with TC engines by $0.5 \%$. Since an FVVT affects the whole engine map of an NA engine, its positive effect is greater for NA engines than for TC engines.
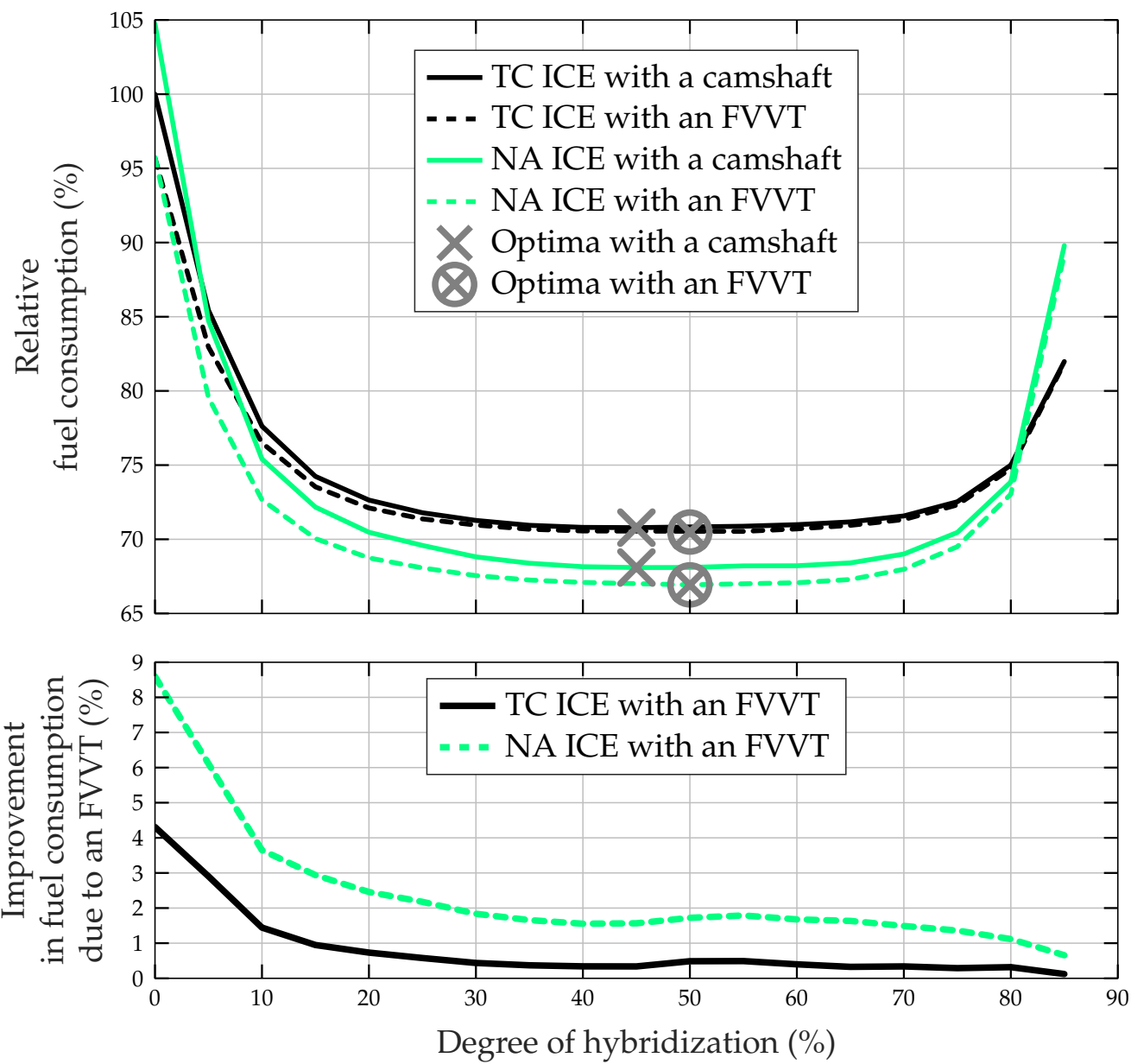

Figure 8. Relative fuel consumption of all HEVs investigated in charge-sustaining operation as a function of the $\mathrm{DOH}$. The upper plot shows the results for naturally aspirated and turbocharged engines equipped either with a camshaft or an FVVT relative to the ICEV with a camshaft-equipped TC engine. The lower plot shows the relative improvement due to the implementation of an FVVT on the respective engines.

Figure 9 shows the operating points of a camshaft-equipped NA ICE on the WLTC for degrees of hybridization of $0 \%, 15 \%$, and $45 \%$. The top row shows the engine efficiency maps with the engine speed on the $x$ axis and the mean effective pressure on the $y$ axis. The patches colored visualize the distribution of the duration for which the ICE is running at a certain operating point. The grid of the patches has a resolution of $200 \mathrm{rpm}$ and $0.5 \mathrm{bar}$ and a patch is only displayed if it contains more than $3 \mathrm{~s}$ of operating duration. All operating points below $1000 \mathrm{rpm}$, i.e., below the minimal speed, are operated with an open clutch. Thus, the fuel flow of these points is computed in Equation (6) with $\omega_{\mathrm{e}}=\omega_{\mathrm{e} \text {,min }}=1000 \mathrm{rpm}$. The middle row shows histograms of the duration of the ICE operated at a certain brake efficiency range. The y axis shows the time in seconds, while on the $x$ axis the brake efficiency of the ICE is arranged in eight bins with a width of five percentage points each. The bottom row shows histograms of the duration of specific 
operation modes. With $T_{\mathrm{e}}$ as ICE torque and $T_{\mathrm{m}}$ as EM torque, the following possible operation modes are defined:

- $\quad$ Boosting, with $T_{\mathrm{e}}>0$ and $T_{\mathrm{m}}>0$,

- $\quad$ EM only, with $T_{\mathrm{e}}=0$ and $T_{\mathrm{m}}>0$,

- ICE only, with $T_{\mathrm{e}}>0$ and $T_{\mathrm{m}}=0$,

- OPS, with $T_{\mathrm{e}}>0$ and $T_{\mathrm{m}}<0$,

- $\quad$ Recuperating, with $T_{\mathrm{e}}=0$ and $T_{\mathrm{m}}<0$.

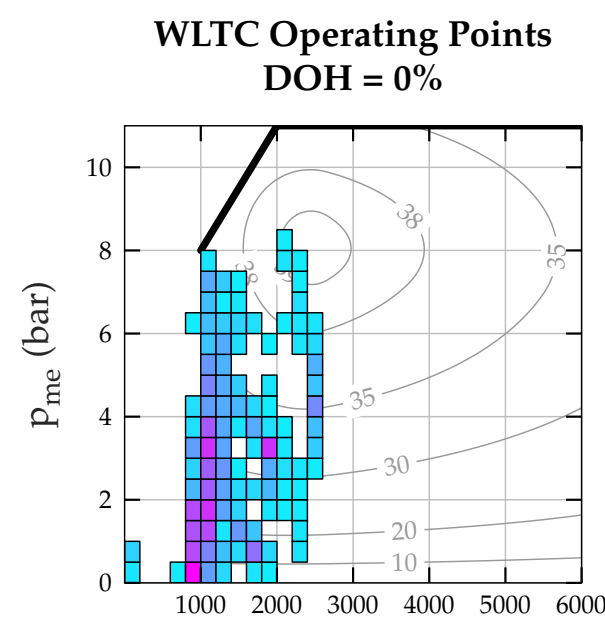

Engine Speed (rpm)
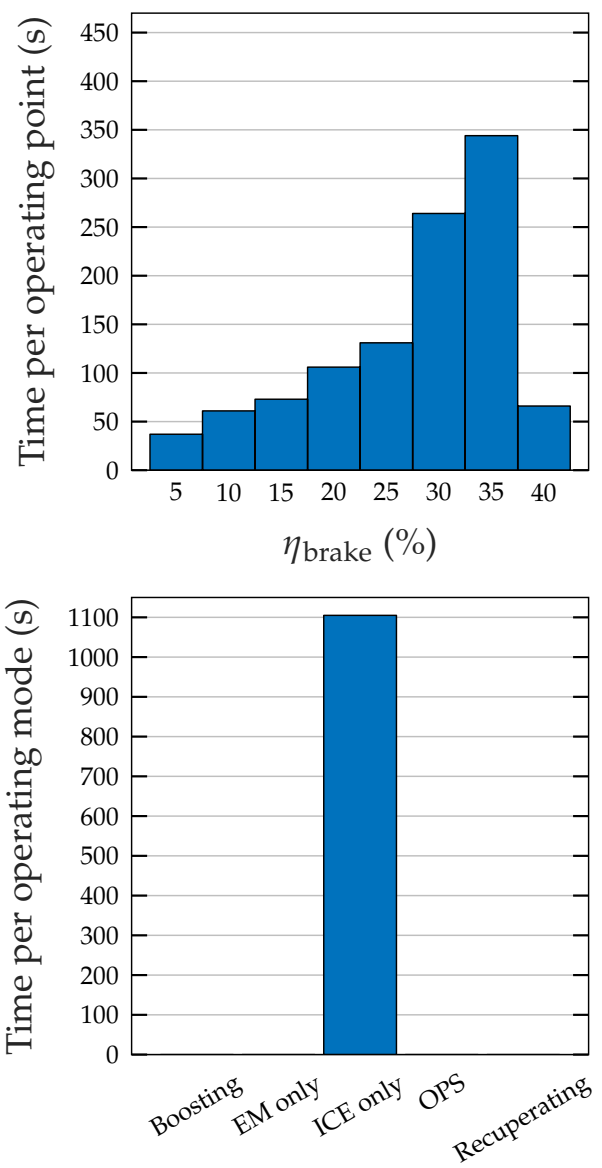

WLTC Operating Points $\mathrm{DOH}=15 \%$

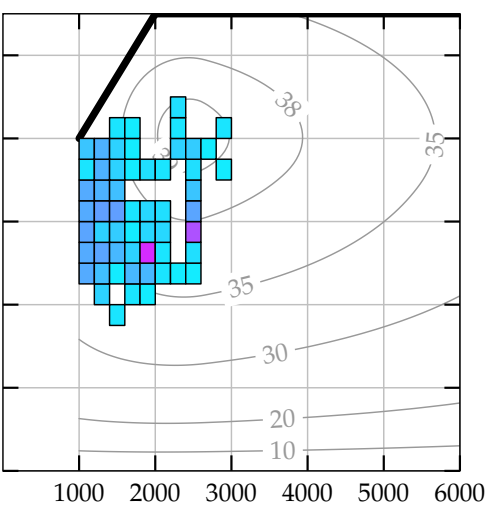

Engine Speed (rpm)
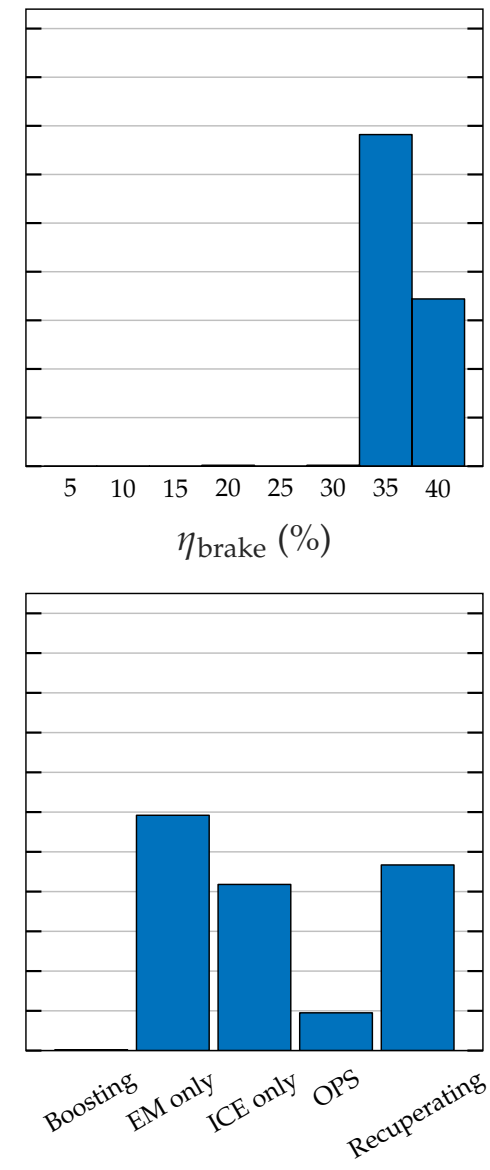

WLTC Operating Points $\mathrm{DOH}=45 \%$

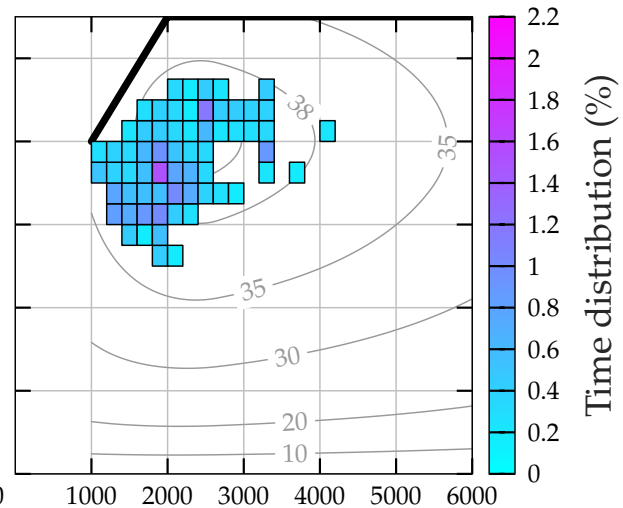

Engine Speed (rpm)
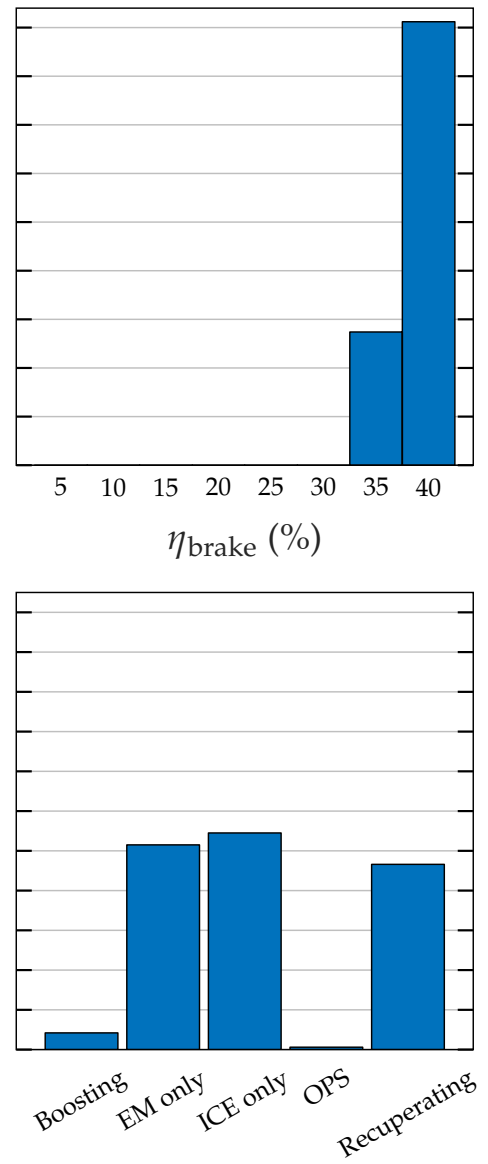

Figure 9. Visualization of the camshaft-equipped NA ICE operation for HEVs with a DOH of $0 \%, 15 \%$, and $45 \%$, respectively. The top row shows the engine maps with time distribution of the operation points. The middle and bottom rows show histograms with the time spent at a specific brake efficiency range and operating mode, respectively. 
In the column on the left-hand side, the results of an ICEV are visualized. In this case, all points of the WLTC are operated with the ICE and, thus, all points appear on the efficiency map of the engine. The points close to an engine speed of $0 \mathrm{rpm}$ originate from the acceleration from standstill and cannot be omitted. The ICE runs at a wide range of brake efficiency, but most often around 30\% to $35 \%$ due to the rather high power demand of the WLTC.

The middle column shows that already with a $\mathrm{DOH}$ of $15 \%$ all operating points below the minimal speed are omitted, i.e., all operating points which in an ICEV would require an open clutch are now driven electrically. Furthermore, the ICE runs almost entirely around a brake efficiency of $35 \%$ to $40 \%$. The electric energy used by the EM is replenished either by recuperating energy from the negative acceleration or by the ICE through an OPS strategy. An OPS strategy brings only an advantage if the ICE is oversized in comparison to the average power demand of a given driving cycle as is the case for an HEV with a DOH of $15 \%$.

The column on the right shows the results of an HEV with a DOH of $45 \%$. The engine operates almost entirely at its best brake efficiency since its size at a DOH of $45 \%$ is well suited for the power demand of the WLTC. The OPS strategy has a very low relevance in this case, since a significant part of the driving cycle is driven already at a high brake efficiency. In contrast, an OPS strategy would increase the load on the engine further, which would lead to a decrease in efficiency. Thus, an OPS strategy is not applied at a sufficiently high DOH, i.e., at an engine size well suited to the WLTC. The part of the driving cycle with the low-load operating points is driven purely electric with the energy gained almost entirely from recuperation.

\subsection{HEV with a Fixed Transmission}

In this section, an HEV with a fixed transmission (FTHEV), i.e., the HEV concept (c) shown in Figure 1, is compared to a conventional HEV as in Section 3.1. The idea behind the FTHEV concept is to offer a simpler vehicle setup to reduce mass and cost which still is able to attain a fuel economy that is similar to that of a conventional HEV.

The top plot of Figure 10 shows the relative fuel consumption over the DOH of HEVs with a varying range of available gears and a camshaft-equipped TC ICE. All points are referenced to the fuel consumption of the camshaft-equipped TC ICEV, i.e., a DOH of $0 \%$, with the gears one to seven available. The black line represents the conventional HEVs at a varying DOH with all gears available, as shown in Figure 8. The colored lines represent HEVs, where the available gear ratios are consecutively reduced. In each step, the highest gear ratio is removed, i.e., the smallest gear. To obtain results comparable to the HEV with all gears available, the initially set acceleration performance cannot be guaranteed for the HEVs with a reduced number of gears since this would lead to a change in the sizing of the ICE and the EM.

The results show that by removing the first two gear ratios the fuel consumption increases by $1.6 \%$ on average. Removing the third gear requires a $\mathrm{DOH}$ of at least $5 \%$ and increases the fuel consumption by $2.6 \%$ on average. Removing the fourth gear leads to a fuel consumption increase of $5.2 \%$ and further decreases the possible range of $\mathrm{DOH}$. Compared to an HEV with all gears available, removing the fifth gear, thus leaving only the two smallest gear ratios, yields an average increase of $12.3 \%$ and a $\mathrm{DOH}$ required of at least $40 \%$. A simulation with the highest gear only is not feasible. The adaptation of the $\mathrm{DOH}$ range is required to enable driving the WLTC in the charge-sustaining mode since the ICE cannot provide enough torque to the wheels if the high gear ratios are removed. Thus, a sufficiently powerful $\mathrm{EM}$, i.e., a certain $\mathrm{DOH}$, is required in order to provide the torque necessary to drive the WLTC. On the other hand, if too many gears are removed, the maximally possible $\mathrm{DOH}$ is reduced, as visible in the last three reduction steps, since the ICE cannot be operated such that the conditions on the final SOC are met. The increase in fuel consumption due to the gear removal is an additional check of the feasibility of the DP algorithm. By reducing the input variables to the DP, that is the number of gears available, the new solution must be suboptimal to the solution with a wider input range. 

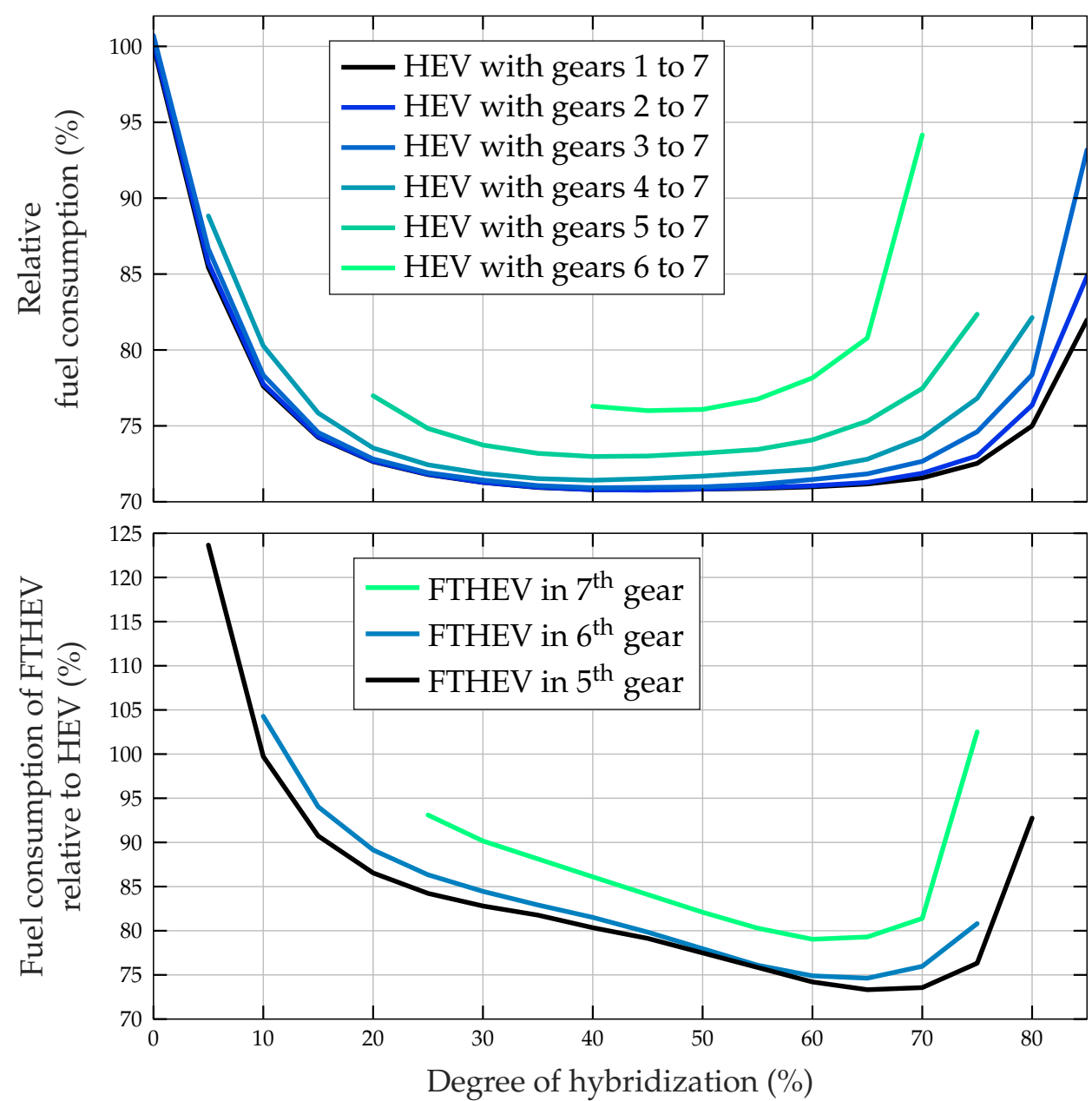

Figure 10. Results of varying the DOH for HEVs and FTHEVs, all with the camshaft-equipped TC engine. The top plot shows the relative fuel consumption of HEVs with varying availability of the gears. As a reference $(=100 \%)$ the fuel consumption of the ICEV, i.e., at a DOH of $0 \%$, with all gears available is taken. The bottom plot shows results for FTHEVs with varying fixed gear ratios, with the fuel consumption relative to the HEV with all gears available at an optimal $\mathrm{DOH}$ of $45 \%$.

The bottom plot shows the fuel consumption of HEVs with a fixed transmission equivalent to the fifth, the sixth, and the seventh gear, respectively. Choosing a lower gear does not yield any feasible results since the maximal engine speed is exceeded due to the rather high peak velocities in the WLTC. Again, the results in this plot are relative to the fuel consumption of the camshaft-equipped TC ICEV, i.e., a DOH of $0 \%$, with the gears one to seven available. In contrast to the upper plot, the acceleration performance is achieved with all vehicles, with each transmission ratio and at each DOH. The FTHEV in the fifth gear achieves its optimal fuel economy at a DOH of $65 \%$, which diverges only by $3.6 \%$ from the fuel consumption of the reference $\mathrm{HEV}$ at the optimal DOH. In the sixth gear, the optimum of the FTHEV is found at a DOH of $65 \%$ as well and shows an increase in fuel consumption of $5.4 \%$ compared to the reference HEV at the optimal DOH. In the seventh gear, the optimum of the FTHEV is found at a DOH of $60 \%$ and the fuel consumption increase by $11.7 \%$ compared to the reference HEV at the optimal DOH. The increase in fuel consumption towards a $\mathrm{DOH}$ of $0 \%$ for all transmission ratios analyzed stems from the significant increase of the required total propulsion power in order to achieve the desired acceleration performance with a fixed transmission ratio. The mass of an FTHEV in the fifth gear and at the optimal DOH is reduced by $1.7 \%$, which is mainly due to the removal of the gearbox. However, to ensure the acceleration performance an increase in the total propulsion power by $27 \%$ is required, which partially compensates for the advantages due to the lighter transmission. 


\subsection{Summary of the Results}

The results show that a significant reduction in fuel consumption is achieved already with a DOH of $25 \%$, which is in accordance with other research [63-65]. For a vehicle with any engine type, i.e., with a TC or an NA engine, equipped with a camshaft or with an FVVT, the DOH for a theoretical fuel-optimal vehicle configuration lies between $45 \%$ and $50 \%$. For very low degrees of hybridization, the implementation of an FVVT allows fuel savings of up to $9 \%$. However, at degrees of hybridization higher than $30 \%$ the advantage of an FVVT decreases to less than $2 \%$. Furthermore, the fuel consumption diverges by less than $2 \%$ from the optimum if the highest two gear ratios are removed from the gearbox in the conventional HEV. Additionally, with a sufficiently high $\mathrm{DOH}$, the transmission of an HEV can be simplified to one fixed gear ratio, which leads to a fuel consumption that is close to that achieved with the conventional HEV.

\section{Conclusions}

In this paper, we investigated the influence of state-of-the-art naturally aspirated and turbocharged internal combustion engines on the degree of hybridization. Furthermore, both engine concepts are evaluated with a conventional camshaft-driven valve train system and a fully variable valve train system. All internal combustion engine models are based on data obtained from measurements on engine test benches. The advantage of the FVVT is its increased efficiency in part-load operating points due to decreased pumping losses and improved combustion concepts such as the x-stroke operation and the cylinder deactivation mode. However, it is not a priori clear to what extent an improvement in part-load efficiency represents an advantage to hybrid electric vehicles. Thus, four different internal combustion engine types are evaluated with two hybrid electric vehicle concepts, one with a conventional gearbox and one with a fixed transmission ratio. They are then compared to non-hybrid vehicles with regard to fuel consumption.

The highlights of this study can be summarized as follows:

- The core components of a hybrid electric powertrain system, such as the internal combustion engine, the electric machine, and the battery, are modeled in high detail with regard to the tank-to-wheel efficiency of the vehicle.

- The models of the internal combustion engines are based on data obtained from measurements on engine test benches. The brake efficiency improvement by up to $40 \%$ by dethrottling and an $\mathrm{x}$-stroke operation has been verified by an internally developed fully variable valve train that was published in [45].

- The acceleration performance is determined by the mass of the vehicle and the available torque of the propulsion system. For the same acceleration performance, an increase of the degree of hybridization from $0 \%$ to $50 \%$ results in a decrease of the total system power of $13.8 \%$ for an HEV with a turbocharged ICE and of $29.2 \%$ for an HEV with a naturally aspirated ICE.

- Compared to non-hybrid vehicles, the optimal fuel consumption for camshaft-equipped engines is achieved at a degree of hybridization of $45 \%$ with a reduction of $29.2 \%$ for HEVs with turbocharged engines and a reduction of $31.9 \%$ for HEVs with naturally aspirated engines. However, the majority of the potential fuel-saving is already achieved with a DOH of $25 \%$ with reductions of $28 \%$ and $30 \%$ for HEVs with turbocharged and naturally aspirated engines, respectively.

- By equipping any of the engines investigated with an FVVT the fuel consumption of a non-hybrid vehicle improves by $4 \%$ to $9 \%$. However, by increasing the degree of hybridization to $10 \%$ the savings amount only to $3 \%$ to $4 \%$ and decrease further to $1 \%$ to $2 \%$ for a $\mathrm{DOH}$ range of $30 \%$ to $60 \%$, depending on the engine type.

- With an increasing degree of hybridization, the internal combustion engine becomes smaller while the electric machine increases in size. At a DOH of $45 \%$, any shifting of the operating point becomes obsolete since the ICE is well suited for the power demand of the chosen driving cycle. 
- At a high $\mathrm{DOH}$, the gearbox becomes obsolete due to the high torque available from the electric machine. Thus, an HEV can be realized with a fixed transmission ratio, which reduces the total mass, improves the mechanical transmission efficiency, and achieves almost the identical fuel consumption as an HEV with all gears available.

In this paper, the potential of various spark-ignited internal combustion engine concepts, such as naturally aspirated, turbocharged, and with or without a fully variable valve train, is quantified for their application to hybrid electric vehicles. The results show that independently of the applied engine concept, hybridization significantly decreases the fuel consumption of the vehicle. Furthermore, at a sufficiently high degree of hybridization, the gearbox can be omitted since the electric machine supplies enough torque at a low rotational speed to allow any dynamic acceleration desired.

Further investigations are required to find a suitable transmission ratio between the internal combustion engine, the electric machine, and the wheels while ensuring that all propulsion components are within reasonable manufacturing ranges. The battery sizing also requires investigations without regard to the size of the electric machine since a vehicle with a small degree of hybridization, but with a high battery capacity might present an advantage to consumers with a certain ratio of urban to extra-urban driving range. Last not but not least, economic aspects must be included since the sizing of components such as power electronics and batteries is more cost-sensitive than the potential optimal fuel consumption.

Author Contributions: Conceptualization, A.O., N.Z., P.S. and C.O.; methodology, A.O. and N.Z.; software, A.O. and N.Z.; validation, A.O.; writing—original draft preparation, A.O.; writing—review and editing, N.Z., P.S. and C.O.; supervision, N.Z., P.S. and C.O.; project administration, P.S. and C.O.; funding acquisition, P.S. and C.O. All authors have read and agreed to the published version of the manuscript.

Funding: This research was partially funded by the Swiss Federal Office of Energy under the contract SI/501619-01.

Acknowledgments: We want to thank Tobias Oesch for their valuable work with the FEM simulations of the electric machine.

Conflicts of Interest: The authors declare no conflict of interest.

$\begin{array}{ll}\text { Abbreviations } \\ \text { ICEV } & \text { Internal combustion engine vehicle } \\ \text { GHG } & \text { Greenhouse gas } \\ \text { PHEV } & \text { Plug-in hybrid electric vehicle } \\ \text { BEV } & \text { Battery electric vehicle } \\ \text { FCV } & \text { Fuel cell vehicle } \\ \text { HEV } & \text { Hybrid electric vehicle } \\ \text { SOC } & \text { State of charge } \\ \text { EM } & \text { Electric machine } \\ \text { ICE } & \text { Internal combustion engine } \\ \text { OPS } & \text { Operating point shift } \\ \text { SI } & \text { Spark-ignited } \\ \text { DOH } & \text { Degree of hybridization } \\ \text { FVVT } & \text { Fully variable valve train } \\ \text { DP } & \text { Dynamic programming } \\ \text { FEM } & \text { Finite elements method } \\ \text { FTHEV } & \text { Fixed transmission hybrid electric vehicle } \\ \text { WLTC } & \text { Worldwide harmonized light vehicle test cycle } \\ \text { NA } & \text { Naturally aspirated } \\ \text { TC } & \text { Turbocharged } \\ \text { NEDC } & \text { New European driving cycle }\end{array}$




\section{References}

1. Delphi. Worldwide Emissions Standards, Passenger Cars and Light Duty Vehicles 2020/2021. 2021. Available online: https:/ /www.delphi.com/innovations (accessed on 2 December 2021).

2. Limarzo, S.E.; Dickenmann, C.S. Auswirkungen der $\mathrm{CO}_{2}$-Emissionsvorschriften für Neue Personenwagen 2012-2018; Eidgenössisches Departement für Umwelt, Verkehr, Energie und Kommunikation UVEK: Bern, Switzerland, 2020.

3. Harrison, G.; Vilchez, J.J.G.; Thiel, C. Industry strategies for the promotion of E-mobility under alternative policy and economic scenarios. Eur. Transp. Res. Rev. 2018, 10, 19. [CrossRef]

4. Regulation (EU) 2018/842; European Union: Brussels, Belgium, 2018.

5. Regulation (EU) 2019/631; European Union: Brussels, Belgium, 2019.

6. Regulation (EU) 2019/1242; European Union: Brussels, Belgium, 2019.

7. Weldon, P.; Morrissey, P.; O'Mahony, M. Long-term cost of ownership comparative analysis between electric vehicles and internal combustion engine vehicles. Sustain. Cities Soc. 2018, 39, 578-591. [CrossRef]

8. Gómez Vilchez, J.J.; Smyth, A.; Kelleher, L.; Lu, H.; Rohr, C.; Harrison, G.; Thiel, C. Electric Car Purchase Price as a Factor Determining Consumers' Choice and their Views on Incentives in Europe. Sustainability 2019, 11, 6357. [CrossRef]

9. Kim, S.; Lee, J.; Lee, C. Does Driving Range of Electric Vehicles Influence Electric Vehicle Adoption? Sustainability 2017, 9 , 1783. [CrossRef]

10. Anjos, M.F.; Gendron, B.; Joyce-Moniz, M. Increasing electric vehicle adoption through the optimal deployment of fast-charging stations for local and long-distance travel. Eur. J. Oper. Res. 2020, 285, 263-278. [CrossRef]

11. Xiong, R.; Cao, J.; Yu, Q.; He, H.; Sun, F. Critical Review on the Battery State of Charge Estimation Methods for Electric Vehicles. IEEE Access 2018, 6, 1832-1843. [CrossRef]

12. Xie, S.; Hu, X.; Zhang, Q.; Lin, X.; Mu, B.; Ji, H. Aging-aware co-optimization of battery size, depth of discharge, and energy management for plug-in hybrid electric vehicles. J. Power Source 2020, 450, 227638. [CrossRef]

13. Soldo, J.; Škugor, B.; Deur, J. Analysis of optimal battery state-of-charge trajectory patterns for blended mode of a parallel plug-in hybrid electric vehicle and a wide range of driving conditions. Optim. Eng. 2021, 22, 1955-1977. [CrossRef]

14. Riemersma, I.; Mock, P. Too Low to Be True? How to Measure Fuel Consumption and $\mathrm{CO}_{2}$ Emissions of Plug-In Hybrid Vehicles, Today and in the Future; ICCT-The international council on clean transportation: Berlin, Germany, 2017.

15. Ji, W.; Tal, G. Scenarios for transitioning cars from ICEV to BEVs and PHEVs using household level GPS travel data. Transp. Res. Part D Transp. Environ. 2020, 88, 102555. [CrossRef]

16. Frey, H.C.; Zheng, X.; Hu, J. Variability in Measured Real-World Operational Energy Use and Emission Rates of a Plug-In Hybrid Electric Vehicle. Energies 2020, 13, 1140. [CrossRef]

17. Zhou, B.; Zhang, S.; Wu, Y.; Ke, W.; He, X.; Hao, J. Energy-saving benefits from plug-in hybrid electric vehicles: Perspectives based on real-world measurements. Mitig. Adapt. Strateg. Glob. Chang. 2017, 23, 735-756. [CrossRef]

18. Liu, Y.; Liao, Y.G.; Lai, M.C. Fuel economy improvement and emission reduction of $48 \mathrm{~V}$ mild hybrid electric vehicles with P0, P1, and P2 architectures with lithium battery cell experimental data. Adv. Mech. Eng. 2021, 13, 168781402110360. [CrossRef]

19. Hayslett, S.; Maanen, K.V.; Wenzel, W.; Husain, T. The 48-V Mild Hybrid: Benefits, Motivation, and the Future Outlook. IEEE Electrif. Mag. 2020, 8, 11-17. [CrossRef]

20. Termenon, N.; Lebas, G.; Meert, T. Benefits of Hybrid P2 Off-Line Module Compared to Other Architectures; Springer: Berlin/Heidelberg, Germany, 2019; pp. 334-346. [CrossRef]

21. Alnamasi, K.; Terry, S.; Rocca, A.L.; Cairns, A. Brake Power Availability Led Optimisation of P0 versus P2 48 V Hybrid Powertrain Architectures; SAE International: Pittsburgh, PA, USA, 2020. [CrossRef]

22. Zhuang, W.; Li, S.; Zhang, X.; Kum, D.; Song, Z.; Yin, G.; Ju, F. A survey of powertrain configuration studies on hybrid electric vehicles. Appl. Energy 2020, 262, 114553. [CrossRef]

23. Hao, X.; Lin, Z.; Wang, H.; Ou, S.; Ouyang, M. Range cost-effectiveness of plug-in electric vehicle for heterogeneous consumers: An expanded total ownership cost approach. Appl. Energy 2020, 275, 115394. [CrossRef]

24. Song, Z.; Zhang, X.; Li, J.; Hofmann, H.; Ouyang, M.; Du, J. Component sizing optimization of plug-in hybrid electric vehicles with the hybrid energy storage system. Energy 2018, 144, 393-403. [CrossRef]

25. Zhou, X.; Qin, D.; Yao, M.; Xie, Z. Representation, generation, and optimization methodology of hybrid electric vehicle powertrain architectures. J. Clean. Prod. 2020, 256, 120711. [CrossRef]

26. Anselma, P.G.; Niutta, C.B.; Mainini, L.; Belingardi, G. Multidisciplinary design optimization for hybrid electric vehicles: Component sizing and multi-fidelity frontal crashworthiness. Struct. Multidiscip. Optim. 2020, 62, 2149-2166. [CrossRef]

27. Snoussi, J.; Elghali, S.B.; Benbouzid, M.; Mimouni, M.F. Optimal Sizing of Energy Storage Systems Using Frequency-SeparationBased Energy Management for Fuel Cell Hybrid Electric Vehicles. IEEE Trans. Veh. Technol. 2018, 67, 9337-9346. [CrossRef]

28. Anselma, P.G.; Huo, Y.; Roeleveld, J.; Belingardi, G.; Emadi, A. Slope-Weighted Energy-Based Rapid Control Analysis for Hybrid Electric Vehicles. IEEE Trans. Veh. Technol. 2019, 68, 4458-4466. [CrossRef]

29. Kim, K.; Kim, N.; Jeong, J.; Min, S.; Yang, H.; Vijayagopal, R.; Rousseau, A.; Cha, S.W. A Component-Sizing Methodology for a Hybrid Electric Vehicle Using an Optimization Algorithm. Energies 2021, 14, 3147. [CrossRef]

30. Yao, M.; Qin, D.; Zhou, X.; Zhan, S.; Zeng, Y. Integrated optimal control of transmission ratio and power split ratio for a CVT-based plug-in hybrid electric vehicle. Mech. Mach. Theory 2019, 136, 52-71. [CrossRef] 
31. Huang, Y.; Surawski, N.C.; Organ, B.; Zhou, J.L.; Tang, O.H.; Chan, E.F. Fuel consumption and emissions performance under real driving: Comparison between hybrid and conventional vehicles. Sci. Total Environ. 2019, 659, 275-282. [CrossRef] [PubMed]

32. Al-Samari, A. Study of emissions and fuel economy for parallel hybrid versus conventional vehicles on real world and standard driving cycles. Alex. Eng. J. 2017, 56, 721-726. [CrossRef]

33. Dong, H.; Fu, J.; Zhao, Z.; Liu, Q.; Li, Y.; Liu, J. A comparative study on the energy flow of a conventional gasoline-powered vehicle and a new dual clutch parallel-series plug-in hybrid electric vehicle under NEDC. Energy Convers. Manag. 2020, $218,113019$. [CrossRef]

34. Liu, B.; Li, L.; Wang, X.; Cheng, S. Hybrid Electric Vehicle Downshifting Strategy Based on Stochastic Dynamic Programming during Regenerative Braking Process. IEEE Trans. Veh. Technol. 2018, 67, 4716-4727. [CrossRef]

35. Liu, X.; Qin, D.; Wang, S. Minimum Energy Management Strategy of Equivalent Fuel Consumption of Hybrid Electric Vehicle Based on Improved Global Optimization Equivalent Factor. Energies 2019, 12, 2076. [CrossRef]

36. Enang, W.; Bannister, C. Modelling and control of hybrid electric vehicles (A comprehensive review). Renew. Sustain. Energy Rev. 2017, 74, 1210-1239. [CrossRef]

37. Engbroks, L.; Görke, D.; Schmiedler, S.; Strenkert, J.; Geringer, B. Applying forward dynamic programming to combined energy and thermal management optimization of hybrid electric vehicles. IFAC-PapersOnLine 2018, 51, 383-389. [CrossRef]

38. Salazar, M.; Houshmand, A.; Cassandras, C.G.; Pavone, M. Optimal Routing and Energy Management Strategies for Plug-in Hybrid Electric Vehicles. In Proceedings of the 2019 IEEE Intelligent Transportation Systems Conference (ITSC), Auckland, New Zealand, 27-30 October 2019. [CrossRef]

39. Polverino, P.; Arsie, I.; Pianese, C. Optimal Energy Management for Hybrid Electric Vehicles Based on Dynamic Programming and Receding Horizon. Energies 2021, 14, 3502. [CrossRef]

40. Wegmann, R.; Döge, V.; Becker, J.; Sauer, D.U. Optimized operation of hybrid battery systems for electric vehicles using deterministic and stochastic dynamic programming. J. Energy Storage 2017, 14, 22-38. [CrossRef]

41. Zhang, F.; Wang, L.; Coskun, S.; Pang, H.; Cui, Y.; Xi, J. Energy Management Strategies for Hybrid Electric Vehicles: Review, Classification, Comparison, and Outlook. Energies 2020, 13, 3352. [CrossRef]

42. Peng, H.; Li, J.; Thul, A.; Deng, K.; Ünlübayir, C.; Löwenstein, L.; Hameyer, K. A scalable, causal, adaptive rule-based energy management for fuel cell hybrid railway vehicles learned from results of dynamic programming. eTransportation 2020, 4, 100057. [CrossRef]

43. Rezaei, A.; Burl, J.B.; Zhou, B.; Rezaei, M. A New Real-Time Optimal Energy Management Strategy for Parallel Hybrid Electric Vehicles. IEEE Trans. Control Syst. Technol. 2019. 27, 830-837. [CrossRef]

44. Balmelli, M.; Zsiga, N.; Merotto, L.; Soltic, P. Effect of the Intake Valve Lift and Closing Angle on Part Load Efficiency of a Spark Ignition Engine. Energies 2020, 13, 1682. [CrossRef]

45. Omanovic, A.; Zsiga, N.; Soltic, P.; Onder, C. Increased Internal Combustion Engine Efficiency with Optimized Valve Timings in Extended Stroke Operation. Energies 2021, 14, 2750. [CrossRef]

46. Bertsekas, D. Dynamic Programming and Optimal Control; Athena Scientific: Belmont, MA, USA, 2005.

47. Ding, N.; Prasad, K.; Lie, T.T. Design of a hybrid energy management system using designed rule-based control strategy and genetic algorithm for the series-parallel plug-in hybrid electric vehicle. Int. J. Energy Res. 2020, 45, 1627-1644. [CrossRef]

48. Anselma, P.G.; Biswas, A.; Belingardi, G.; Emadi, A. Rapid assessment of the fuel economy capability of parallel and series-parallel hybrid electric vehicles. Appl. Energy 2020, 275, 115319. [CrossRef]

49. Tran, M.K.; Akinsanya, M.; Panchal, S.; Fraser, R.; Fowler, M. Design of a Hybrid Electric Vehicle Powertrain for Performance Optimization Considering Various Powertrain Components and Configurations. Vehicles 2020, 3, 20-32. [CrossRef]

50. Webpage of the Institute for Dynamic Systems and Control of ETHZ. Available online: https://idsc.ethz.ch/research-guzzellaonder/downloads.html (accessed on 11 November 2021).

51. Gross, E. On the Bellman's principle of optimality. Phys. A Stat. Mech. Appl. 2016, 462, 217-221. [CrossRef]

52. Sundström, O.; Ambühl, D.; Guzzella, L. On Implementation of Dynamic Programming for Optimal Control Problems with Final State Constraints. Gas Sci. Technol. Rev. Inst. Fr. Pét. 2009, 65, 91-102. [CrossRef]

53. Elbert, P.; Ebbesen, S.; Guzzella, L. Implementation of Dynamic Programming for $n$-Dimensional Optimal Control Problems with Final State Constraints. IEEE Trans. Control Syst. Technol. 2013. 21, 924-931. [CrossRef]

54. Kargul, J.; Stuhldreher, M.; Barba, D.; Schenk, C.; Bohac, S.; McDonald, J.; Dekraker, P.; Alden, J. Benchmarking a 2018 Toyota Camry 2.5-Liter Atkinson Cycle Engine with Cooled-EGR; SAE Technical Paper Series; SAE International: Pittsburgh, PA, USA, 2019. [CrossRef]

55. van Basshuysen, R.; Schäfer, F. (Eds.) Handbuch Verbrennungsmotor; Springer Fachmedien Wiesbaden: Wiesbaden, Germany, 2017. [CrossRef]

56. Guzzella, L.; Onder, C.H. Introduction to Modeling and Control of Internal Combustion Engine Systems; Springer: Berlin/Heidelberg, Germany, 2010. [CrossRef]

57. Yang, Z.; Shang, F.; Brown, I.P.; Krishnamurthy, M. Comparative Study of Interior Permanent Magnet, Induction, and Switched Reluctance Motor Drives for EV and HEV Applications. IEEE Trans. Transp. Electrif. 2015, 1, 245-254. [CrossRef]

58. Mahmoudi, A.; Soong, W.L.; Pellegrino, G.; Armando, E. Loss Function Modeling of Efficiency Maps of Electrical Machines. IEEE Trans. Ind. Appl. 2017, 53, 4221-4231. [CrossRef] 
59. Zhu, Z.Q.; Chu, W.Q.; Guan, Y. Quantitative comparison of electromagnetic performance of electrical machines for HEVs/EVs. CES Trans. Electr. Mach. Syst. 2017, 1, 37-47. [CrossRef]

60. Panasonic Data Sheet NCR-18650B. https://www.imrbatteries.com/content/panasonic_ncr18650b-2.pdf (accessed on 11 November 2021).

61. Guzzella, L.; Sciarretta, A. Vehicle Propulsion Systems; Springer: Berlin/Heidelberg, Germany, 2013. [CrossRef]

62. Zsiga, N.; Omanovic, A.; Soltic, P.; Schneider, W. Functionality and Potential of a New Electrohydraulic Valve Train. MTZ Worldw. 2019, 80, 18-27. [CrossRef]

63. Lukic, S.; Emadi, A. Effects of Drivetrain Hybridization on Fuel Economy and Dynamic Performance of Parallel Hybrid Electric Vehicles. IEEE Trans. Veh. Technol. 2004, 53, 385-389. [CrossRef]

64. Ott, T.; Zurbriggen, F.; Onder, C.; Guzzella, L. Cycle-averaged efficiency of hybrid electric vehicles. Proc. Inst. Mech. Eng. Part D J. Automob. Eng. 2012, 227, 78-86. [CrossRef]

65. Ebbesen, S.; Elbert, P.; Guzzella, L. Engine Downsizing and Electric Hybridization under Consideration of Cost and Drivability. Oil Gas Sci. Technol. Rev. IFP Energies Nouv. 2012, 68, 109-116. [CrossRef] 